\title{
Organic corrosion inhibitors: where are we now? A review. Part IV. Passivation and the role of mono- and diphosphonates ${ }^{1}$
}

\author{
Yu.I. Kuznetsov \\ A.N. Frumkin Institute of Physical Chemistry and Electrochemistry, Russian Academy \\ of Sciences, Leninskii pr. 31, Moscow, 119071 Russian Federation \\ E-mail: kuznetsov@ipc.rssi.ru
}

\begin{abstract}
This article continues the review of studies (2006-2016) dealing with the passivation of various metals by solutions of organic corrosion inhibitors. It provides an overview of papers on the passivating properties of mono- and diphosphonic acids and their salts. The results of corrosion and electrochemical studies, as well as studies on the composition and structural features of surface layers on metals by a variety of physicochemical methods are considered.
\end{abstract}

Key words: corrosion inhibitors, metal passivation, phosphonic acids, self-assembled monolayers.

Received: September 16, 2017. Published: October 3, 2017.

doi: $\underline{10.17675 / 2305-6894-2017-6-4-3}$

Phosphonic acids form an extensive class of phosphorus-containing organic compounds with general formula $\mathrm{R}-\mathrm{P}(\mathrm{O})(\mathrm{OH})_{2}$, so it is evident that the simplest of them are dibasic acids. Even they are capable of forming a four-membered chelate cycle with cations of certain metals. Phosphonic acids can also be polybasic, such as, for example, the widely known nitrilotris(methylenephosphonic) (NTP) or 1-hydroxyethylidene diphosphonic (HEDP) acids, respectively, with the formulas:
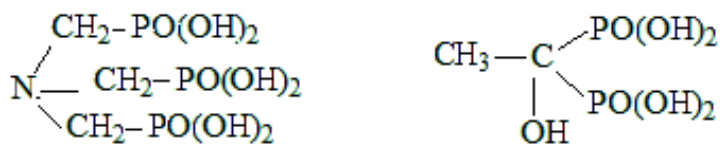

Such compounds are often called phosphonate complexons, because they contain basic and acidic donor centers that interact with metal cations to form at least two cycles ensuring a high stability of complex compounds [1]. Complexons are often called chelating ligands, and their complex compounds are called chelates. The high saturation of many complexons with functional groups makes them capable of complexing with cations of

\footnotetext{
${ }^{1}$ This study was carried out at A.N. Frumkin Institute of physical chemistry and electrochemistry of the Russian Academy of Sciences and was financially supported by the Russian Science Foundation (Grant No. 17-13-01413 "Fundamental aspects of formation of ultrathin passivating films from organic compounds in protection from atmospheric corrosion").
} 
various metals, thus opening the possibility for phosphonic acids to be chemisorbed and for the complexes themselves to be used as corrosion inhibitors.

A valuable property of phosphonate complexons and complexonates of metals, especially zinc, is that they can be used in reagent treatment of water for protection against scaling and corrosion. This property is well covered in several books [1-7], many reviews and papers; therefore, it will not be considered here. The main attention will be paid to the passivating ability of mono- and diphosphonates that form self-assembled monolayers (SAMs) on the surface of metals and their oxides.

Although studies of SAMs began as far back as in the 1940s, their intensification in relation to the protection of metals and their passivation started much later. In this function, phosphonates are of great interest not only as an anticorrosive means, but also as adhesion promoters for polymer coatings [8-10]. It should be noted that the widespread practical use of SAMs for the passivation of metals was apparently hampered by the long time of their formation and the frequent need for the use of inflammable solvents. In recent years, the range of phosphonic compounds used for passivating modification of technical metals and methods of its implementation has increased significantly, so we can hope that their practical application will also increase.

\section{Mono- and diphosphonic acids and their salts}

The possibility of using alkylphosphonic acids to form SAM on engineering metals such as $\mathrm{Fe}, \mathrm{Al}, \mathrm{Cu}$ and their alloys was demonstrated back in the 1990s. For example, Van Alsten [10] found a good correlation between the length of the SAM main chain and the characteristics of the "coated metal/SAM/polymer" system, and also considered the effect of treatment time when self-assembly occurs directly from the binder polymer phase. $\mathrm{He}$ came to the conclusion that the procedure for the production of SAM using alkylphosphonic acids on conventional engineering metals is a versatile way for modifying their surface. It was found that $\alpha, \omega$-metal-bisphosphonate SAMs, formed due to complexation of organic acids and acid-containing polymers (fluoropolymers and copolymers of methacrylic acid), can be used to construct the polymer/SAM/metal interfaces that possess surprising durability.

By the middle of the first decade of this century, it became clear that phosphonic acids are among the main three classes of organic compounds that, like thiols or silanes, can form dense SAMs on many surfaces, including the oxides of practically important oxidized metals (Fe, Al, Ti), thus preventing corrosion of metals and their alloys [11].

Iron and steels. E. Kalman et al. [12] used electrochemical methods to measure the kinetics of formation of SAMs on Armco iron by 1-alkyl-phosphonic acids $\mathrm{CH}_{3}\left(\mathrm{CH}_{2}\right)_{\mathrm{n}} \mathrm{PO}_{3} \mathrm{H}_{2}\left(\mathrm{APhC}_{n+1}\right)$ and $\alpha, \omega$-diphosphonic acids $\mathrm{H}_{2} \mathrm{O}_{3} \mathrm{P}\left(\mathrm{CH}_{2}\right)_{m} \mathrm{PO}_{3} \mathrm{H}_{2}$ (where $n=$ $6,7,8$, or 10 , and $m=7,8$, or 9) in an aqueous solution with $\mathrm{pH} 7.0$ that was adjusted by addition of $\mathrm{NaOH}$. They found that the corrosion potential $\left(E_{\mathrm{cor}}\right)$ of $\mathrm{Fe}$ in an aqueous solution containing $1.0 \mathrm{mmol} \mathrm{APhC}_{10}$ changed relatively slowly and reached its maximal 
value after 4 days. The authors interpreted this as direct evidence about adsorption of corrosion inhibitors and its influence on the dissolution rate of iron.

The protective properties of $\mathrm{APhC}_{n+1}$ on iron surface were characterized by EIS method after 6 days of electrode immersion in the aqueous solution. In this case, interpretation of electrochemical measurements was based on the equivalent circuit shown in Figure 1. In this circuit, $R_{\mathrm{p}}$, i.e., polarization resistance, is the resistance to charge transfer of $\mathrm{Fe}$ dissolution in pores/pinholes of the adsorption layer. This value provides information about the quality of the film.

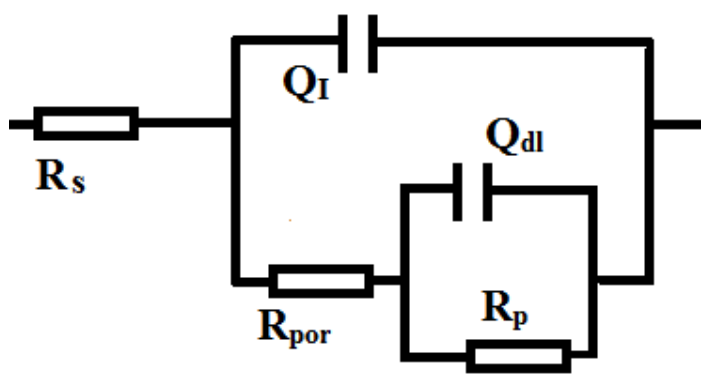

Figure 1. Equivalent circuit proposed to simulate the impedance of modified iron [12]. $R_{\mathrm{S}}$ is solution resistance; $R_{\mathrm{p}}$ is polarization resistance; $R_{\text {por }}$ is pore resistance of the surface layer (SAM); $Q_{\mathrm{dl}}$ is CPE of the double layer; $Q_{\mathrm{I}}$ is CPE of the surface layer.

The interface was described by nonideal, frequency dependent capacitance $\left(Z_{\mathrm{CPE}}=\right.$ $\left.1 /\left[Q(j \omega)^{\alpha}\right]\right)$ and deviation from an ideal capacitance was attributed to the inhomogeneity of the substrate metal. The interfacial capacitance was mainly determined by the properties of the SAM formed. It was found that $Q_{\mathrm{dl}}$ strongly depends on the length of the adsorbate molecules. When organic molecules were adsorbed, the structure of the double layer changed, leading to a decrease in $Q_{\mathrm{dl}}$. The longer the molecule, the smaller the $Q_{\mathrm{dl}}$ value and a stronger interaction between the alkyl chains can be assumed.

A continuous increase in $R_{\mathrm{p}}$ with increasing duration of electrode exposure in the solution was observed for all the alkyl phosphonates studied. Their adsorption layers significantly reduced the dissolution rate of Fe. Together with the decrease in $Q_{\mathrm{dl}}$ values, an increase in the $\alpha$ exponent of CPE can be observed, suggesting a decrease in interface inhomogeneity during adsorption. The authors concluded that, judging by the $R_{\mathrm{p}}$ values obtained after prolonged exposure of the electrode in solution (several days), the protective layer had a continuous and dense structure. At the same time, the value of $Q_{\mathrm{I}}$ characterizing the surface layer also slowly decreases with increasing chain length.

The authors also studied the formation of protective layers on Fe by $\alpha, \omega$-diphosphonic acids and found some difference between it and the formation of adsorption layers by the APhs discussed above. Although an ordered structure and orientation of diphosphonates were observed to a certain degree, only qualitative information could be gained. In addition, the maximum protection was achieved after 4 days of adsorption, suggesting the completion of surface layer formation, whereas in the case of adsorption of monophosphonates, it continued to improve even after 10 days. 
Based on the results of these and polarization studies, it was concluded that monoand diphosphonic compounds with long alkyls are capable of forming adsorption layers with a significant protective effect. The main difference between them, according to the authors, is that monophosphonates can form monolayers, providing hydrophobization of the surface of iron surface, while diphosphonates can form thin polymolecular layers due to the intermolecular interaction between phosphonate groups.

An investigation of the protective properties of $\alpha, \omega$-diphosphonic acids with respect to Fe was continued in [13]. A significant decrease in the anodic currents with increasing adsorption time was observed in the region of active Fe dissolution potentials, which was considered by the authors as a confirmation of the assumption that this process takes place only on uncovered sites of the metal surface. No effect of adsorption duration on the current density in the passive state of the electrode or on the cathodic reaction of $\mathrm{O}_{2}$ reduction was observed. Since the authors believe that the use of $\mathrm{H}_{2} \mathrm{O}_{3} \mathrm{P}-\left(\mathrm{CH}_{2}\right)_{m}-\mathrm{PO}_{3} \mathrm{H}_{2}$ as adhesion promoters is more promising than the use of APhs, their ability for "self-healing" of a thin protective layer was studied. For this purpose, after a passive film was formed for 4 days on the electrode, a scratch was made on the electrode using a sharp knife, and it was ascertained that complete healing of the artificial defect occurred in $3 \mathrm{~h}$.

It should be added that the investigated alkyl monophosphates are substantially more hydrophobic than $\mathrm{H}_{2} \mathrm{O}_{3} \mathrm{P}-\left(\mathrm{CH}_{2}\right)_{m}-\mathrm{PO}_{3} \mathrm{H}_{2}$, which, if adsorbed by two phosphonate groups, appear to form a less densely packed adsorption monolayer. In the second part of this review [14], a similar situation observed by Japanese researchers was already discussed when comparing the adsorption of mono- and $\alpha, \omega$-dicarboxylates on iron. On the other hand, if just one phosphonic group serves as the "anchor" group, the terminal second hydrophilic phosphonic group prevents the surface hydrophobization and remains free to form complexes with the metal cations present in the solution, including $\mathrm{Fe}^{n+}$.

The situation can change if two phosphonate groups are located on one side of the molecule and are linked together through a bridging group, e.g., $-\mathrm{CH}_{2} \mathrm{~N}(\mathrm{Alk})-\mathrm{CH}_{2}-$, as in $N$-tetradecyl- $N$-dimethylenediphosphonic acid whose adsorption on low-carbon steel in a wide $\mathrm{pH}$ range $(7 \leq \mathrm{pH} \leq 13)$ was investigated in [15]. In this case, a more dense packing of organic anions is possible, and the relatively long alkyl imparts good barrier properties to the phosphonate film. When $\mathrm{Me}^{2+}$ cations are present in the solution, they can serve as a cross-linking bridge, as shown in Figure 2. Cations such as $\mathrm{Ca}^{2+}, \mathrm{Mg}^{2+}, \mathrm{Fe}^{2+}, \mathrm{Zn}^{2+}$, etc., can play this role.

It should be recognized that over the past decade, much more work had been devoted to studies on the protection of Fe and steels from corrosion by APhs than by alkyl diphosphonates. These studies can be divided into two groups. The first of these includes works in which the protective properties of APhs with a relatively small alkyl length, $\mathrm{C}_{7}-$ $\mathrm{C}_{10}$, were studied, which made it possible to obtain their thin layers, including SAMs, in aqueous solutions [16-26]. In the second group more hydrophobic monophosphonic compounds were studied, mainly octadecylphosphonic acid $\left(\mathrm{APhC}_{18}\right)$, that cannot be applied from aqueous solutions [27-33]. 


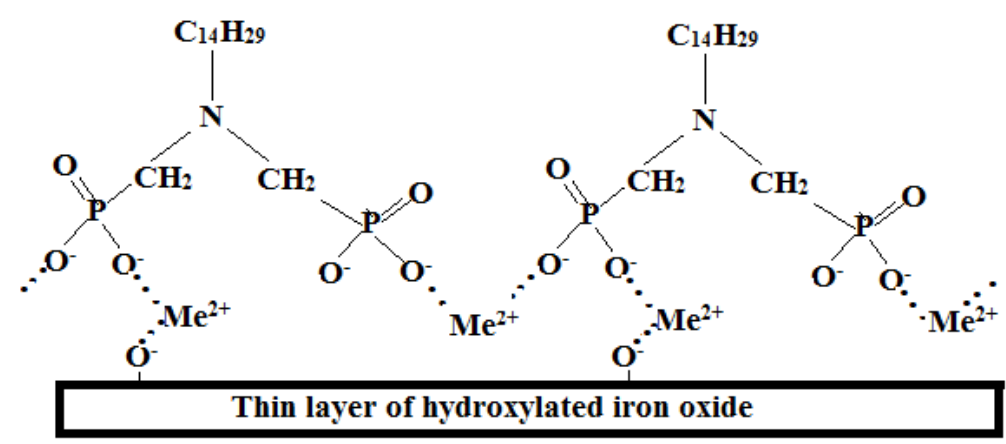

Figure 2. Possible scheme of adsorption of $N$-tetradecyl- $N$-dimethylenediphosphonic acid in the presence of $\mathrm{Ca}^{2+}$ on a steel surface with cross-linking between molecules.

The APhs from the first group adsorbed from aqueous solutions form protective layers on iron surface, which can suppress the dissolution of the metal and stabilize its passive state. It was established in $[16,17]$ that the oxide plays an important role in the adsorption of phosphonates on iron. To obtain a stable oxide film with controlled thickness, potentiostatic passivation of iron in a borate buffer solution with $\mathrm{pH} 8.4$ was carried out. Phosphonate layers were formed by immersion of previously oxidized iron specimens into a $1 \mathrm{mM}$ aqueous solution of $\mathrm{APhC}_{8}$ with $\mathrm{pH} 7.0$ for various periods of time (from $10 \mathrm{~min}$ to $100 \mathrm{~h}$ ). The phosphonate layer on the passive iron surface was studied by SEI, AFM methods [16], conversion electron Mossbauer spectroscopy (CEMS), and X-ray powder diffractometry [17].

It was found that phosphonate groups are more strongly bound to the oxide surface, and the surface of metallic iron is disadvantageous for the formation of a phosphonate layer in aqueous solutions. The value of $R_{\mathrm{p}}$ related to the charge transfer resistance of Fe dissolution in pores and the defectiveness of the adsorption layer was considered as an indicator of the passive layer quality. The change in $R_{\mathrm{p}}$ in time has shown that the rate of anodic dissolution is constantly decreasing due to the time-dependent formation of a protective phosphonate layer.

The kinetics of formation of the phosphonate layer on passive iron is determined by the potential applied previously for the formation of a passive film. The higher the passivating potential applied, the more stable oxide film was formed, providing more favourable substrate for surface interaction of phosphono groups favoring the protective layer formation.

According to the results obtained by CEMS, the relative content of iron oxide/hydroxide in the surface layer decreases during the phosphonation of passive iron. The authors believe that the iron oxide/hydroxide is partially transformed into iron phosphonate, as indicated by the change in morphological homogeneity detected by AFM. Later, supplementing the studies of CEMS with the XPS method, the authors of [18] proved the presence of a phosphonate layer with a thickness of about a monolayer on the passive iron surface. It was shown that in an aqueous $0.1 \mathrm{M} \mathrm{NaClO}_{4}$ solution the value of $R_{\mathrm{p}}$ is higher than $70 \mathrm{kOhm} \cdot \mathrm{cm}^{2}$ and the protective effect $Z$ is higher than $98 \%$. They 
concluded that "the oxide plays an important role in the stability of the protective layer, but the bare surface of iron is disadvantageous for phosphonate binding."

However, introduction of $\mathrm{APhC}_{12}$ in a borate buffer solution with $\mathrm{pH} 7.3$ revealed some important features of its effect on the passivation of mild steel (St3) [19]. $\mathrm{APhC}_{12}$ was introduced into the studied solution containing no corrosive anions in the form of a dispersion in the same buffer, or at $C=5 \mathrm{mmol} / \mathrm{l}$ it was dispersed directly in it. The oxide film formed in air during the preparation of the electrodes was removed by reduction in the solution at a cathodic potential, $E=-0.65 \mathrm{~V}$, for $20 \mathrm{~min}$.

It follows from the anodic polarization curves of steel obtained after the cathodic reduction of the primary oxide film in the deaerated $1.0 \mathrm{mM} \mathrm{PhC}_{12}$ solution that the passivation current density decreases by almost an order of magnitude, and when it was increased to $5 \mathrm{mM}$, the curve showed no active dissolution of steel and $E_{\text {cor }}$ increased by $0.30 \mathrm{~V}$ (Figure 3).

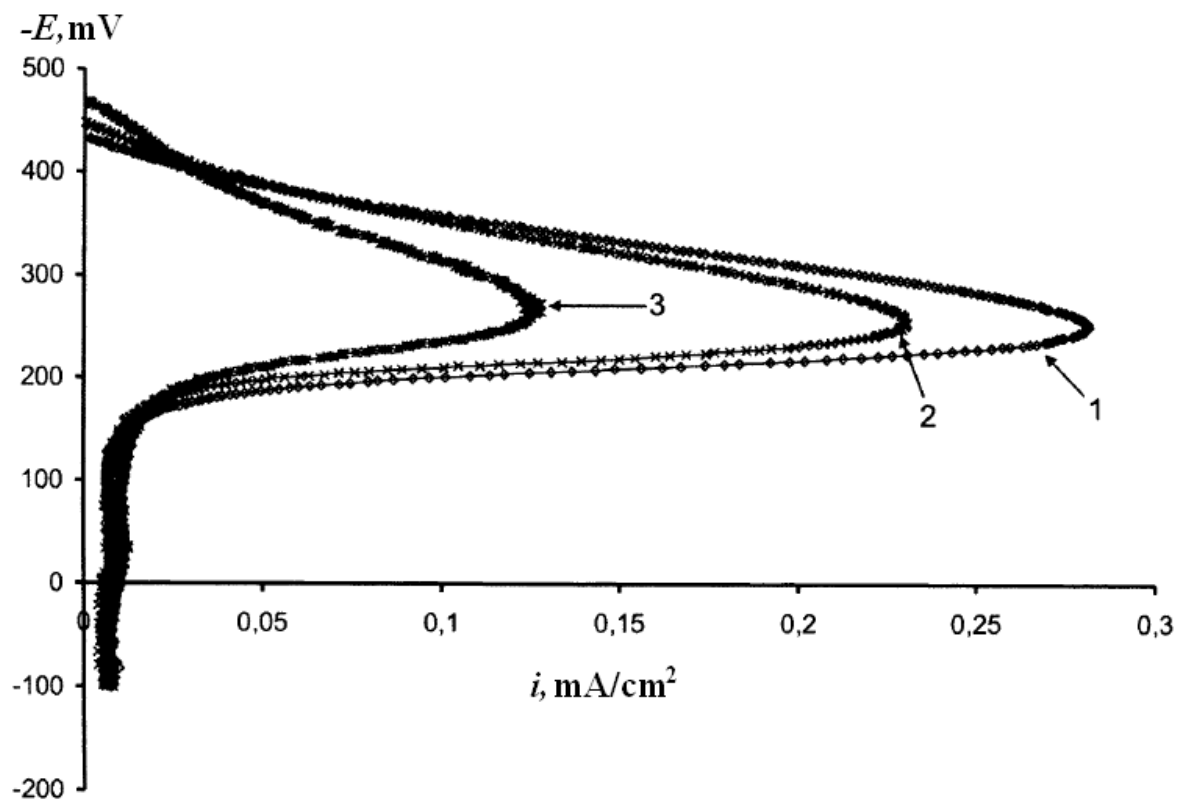

Figure 3. Anodic polarization curves of St3 low-carbon steel in a deaerated borate buffer solution with $\mathrm{pH} 7.3$ containing $\mathrm{APhC}_{12}$ (in mmol/l): $1-0.0 ; 2-1.0 ; 3-5.0$ [19].

It is significant, as the authors have previously shown, that the presence of $\mathrm{APhC}_{12} \mathrm{Na}_{2}$ in the solution does not prevent the reduction of the oxide film. However, for steel electrodes sealed at $E=0.2 \mathrm{~V}$ in a buffer solution without and in the presence of $5 \mathrm{mM}$ $\mathrm{APhC}_{12}$, there is a significant difference in the dependence of $E$ on time $(\tau)$ during galvanostatic cathodic polarization at $i=10 \mu \mathrm{A} / \mathrm{cm}^{2}$. In the first case, the delay of the potential characteristic of iron oxide reduction was observed on the $E=f(\tau)$ curve, whereas it was completely absent in the second case (Figure 4). This fact allowed the authors to assume that $\mathrm{APhC}_{12}$ is able to protect $\mathrm{St} 3$ by the "nonoxide passivation" mechanism in a manner similar to that previously proved for the anions of certain higher carboxylic acids $[4,14]$. 


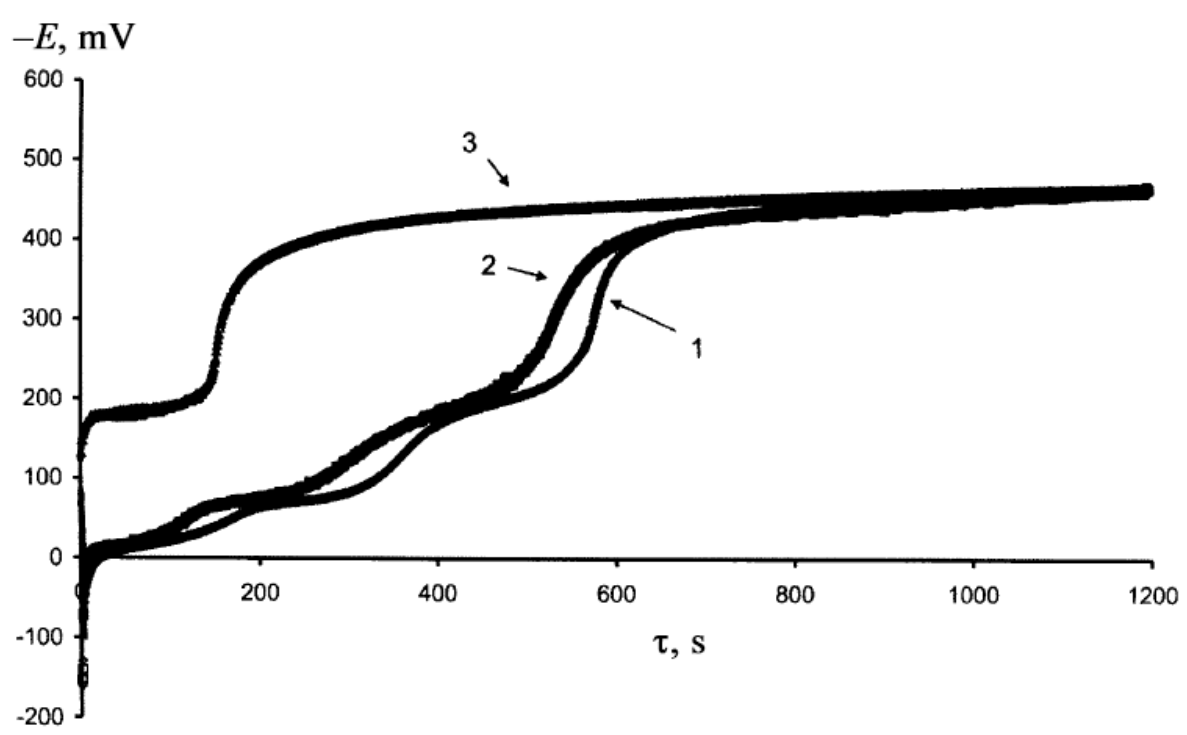

Figure 4. Chronopotentiograms of St3 steel in deaerated borate buffer solution with $\mathrm{pH} 7.3$ at cathodic polarization, $i=10 \mu \mathrm{A} / \mathrm{cm}^{2}$, after passivation of the electrode: 1 - by anodic polarization in borate buffer to $E=0.2 \mathrm{~V} ; 2$ - same, but with an exposure time of $10 \mathrm{~min}$ at $E=0.2 \mathrm{~V} ; 3$ - by anodic polarization, but with preliminary cathodic activation in the presence of $5 \mathrm{mM} \mathrm{APhC}_{12}$ rather that in the pure buffer [19].

The composition of the passivating layers on steel in an $\mathrm{APhC}_{12} \mathrm{Na}_{2}$ solution was also studied by means of reflectance Fourier transform IR-spectrometry (FTIR). It was found that the maximum amount of adsorbed phosphonate is observed when cathodic surface reduction is carried out in the presence of $\mathrm{APhC}_{12} \mathrm{Na}_{2}$ in deaerated buffer. Although the IRstudy did not confirm the formation of any $\mathrm{APhC}_{12} \mathrm{Na}_{2}$ compound with iron, the authors suggested that the passivation of steel is not accompanied by the formation of an oxide, but is due to the chemisorption of phosphonate on the freshly formed steel surface during the reduction of the oxide on it.

The anodic behavior of low-carbon steel in a borate buffer solution in the presence of sodium salts of APhs with general formula $\mathrm{C}_{n} \mathrm{H}_{2 n} \mathrm{PO}_{3}, n=7-10$, was studied in our laboratory as well $[20,21]$. The best passivating ability was observed in the case of octylphosphonate $\left(\mathrm{APhC}_{8}\right)$, which was studied in more detail. It was found that the standard time of the electrode exposure in the solution prior to $E_{\text {cor }}$ stabilization (15 min) is insufficient in the case of $\mathrm{APhC}_{8}$. Its potential continues to change and is stabilized only in 1.0-1.5 hours. At the same time, $0.3 \mathrm{mmol} / 1$ of $\mathrm{APhC}_{8}$ ensures the transfer of steel into a passive state and slightly improves its stability, judging by the increase in $E_{\mathrm{pt}}$ (Figure 5a). With an increase in $t$ to $60^{\circ} \mathrm{C}$, an even smaller $C_{\text {in }}=0.1 \mathrm{mmol} / 1$ of $\mathrm{APhC}_{8} \mathrm{Na}_{2}$ is required for spontaneous passivation of steel, although in this solution the passivation is unstable and the value of $E_{\mathrm{pt}}$ is more negative than in the initial buffer (Figure $5 \mathrm{~b}$ ). This behavior of steel was explained by the fact that $\mathrm{APhC}_{8}$ can prevent the oxide film growth on steel. The concentration of the corrosion inhibitor is too low to withstand competition in adsorption with corrosive $\mathrm{Cl}^{-}$since $C_{\mathrm{Cl}^{-}}$is two orders of magnitude higher. With the growth of $C_{\mathrm{in}}$ the 
lack of steel protection by $\mathrm{APhC}_{8} \mathrm{Na}_{2}$ disappears and $E_{\mathrm{pt}}$ increases. In addition, it was also shown there that $\mathrm{APhC}_{8} \mathrm{Na}_{2}$ is well adsorbed on both the reduced (at $E=-0.65 \mathrm{~V}$ ) and preoxidized (at $E=0.29 \mathrm{~V}$ ) steel surface. Its adsorption can be adequately described by the Frumkin isotherm with $\left(-\Delta G_{\mathrm{a}}^{0}\right)=36.31 \mathrm{~kJ} / \mathrm{mol} ; a=1.46$ and $29.63 \mathrm{~kJ} / \mathrm{mol} ; a=1.45$, respectively. It is easy to see that $\mathrm{APhC}_{8}$ is better adsorbed on a clean than on oxidized surface of low-carbon steel. This conclusion is different from that made by Hungarian researchers $[15,16]$ who studied the behavior of Fe in aqueous perchlorate solutions. The difference in the adsorption of anionic corrosion inhibitors on Fe and low-carbon steel has already been discussed in $[14,22]$ with respect to salts of carboxylic acids. However, while the transition at $E=-0.65 \mathrm{~V}$ from a pure Fe electrode to low-carbon steel whose surfaces are free of an oxide film attenuated the adsorption of an effective corrosion inhibitor sodium flufenaminate, adsorption is enhanced in the case of $\mathrm{APhC}_{8}$. From a practical point of view, this is an advantage of $\mathrm{APhC}_{8}$.
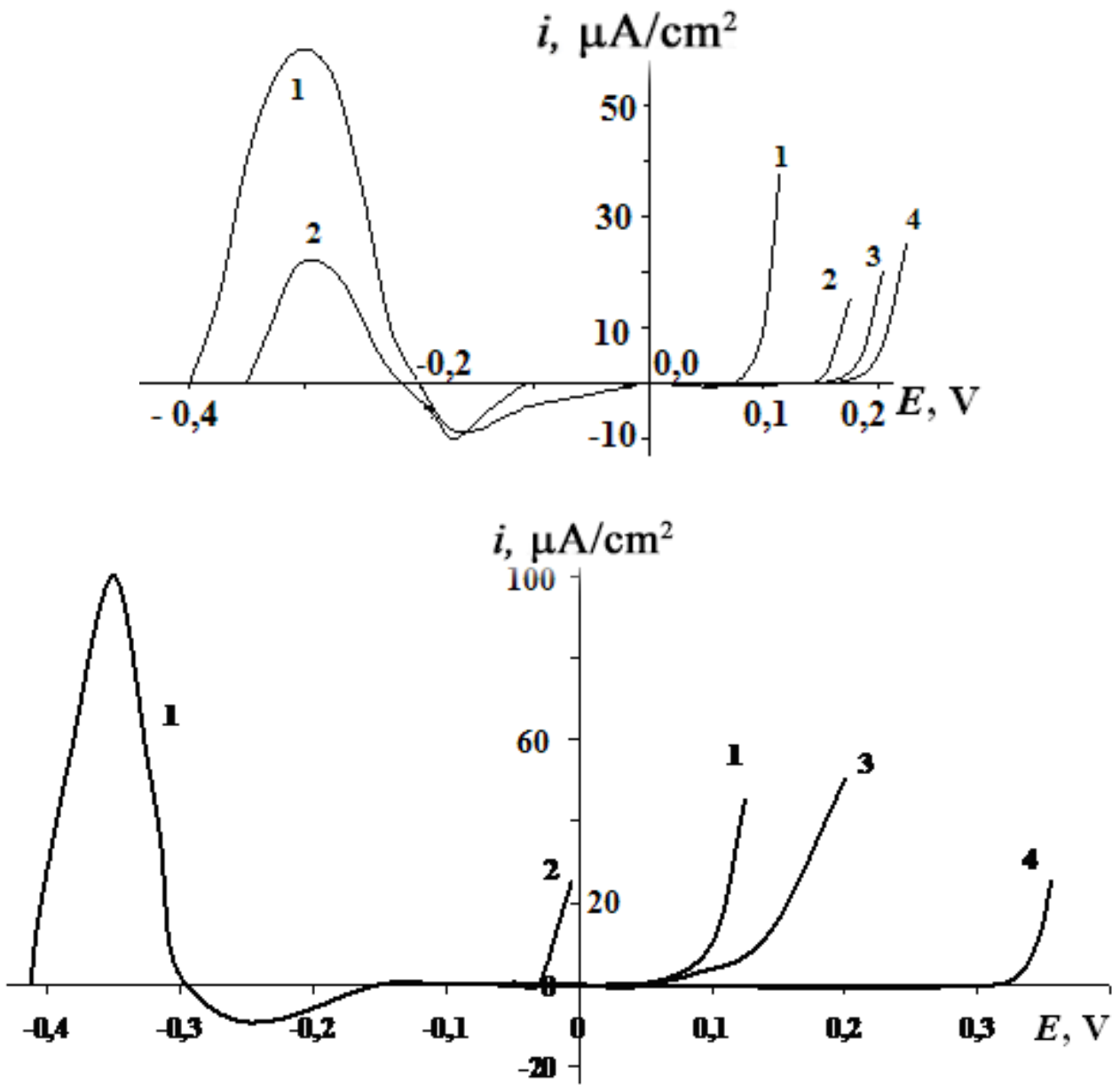

Figure 5. Anodic polarization curves of low-carbon steel in a borate buffer solution ( $\mathrm{pH} 7.4)$ containing $0.01 \mathrm{M} \mathrm{NaCl}$ and $\mathrm{APhC}_{8}$ at concentrations, mmol/1 [20]: a) at $t=20^{\circ} \mathrm{C}, 1-0.0$; $2-0.2 ; 3-0.3 ; 4-4.0 ;$ b) at $t=60^{\circ} \mathrm{C}, 1-0.0 ; 2-0.1 ; 3-1.5 ; 4-3.0$. 
Yet another peculiarity of the passivating properties of $\mathrm{APh}$ is revealed when one considers their effectiveness in the homologous series: $\mathrm{APhC}_{5}(0.11)-\mathrm{APhC}_{7}(1.17)-$ $\mathrm{APhC}_{8}$ (1.70) $-\mathrm{APhC}_{9}(2.23)-\mathrm{APhC}_{10}$ (2.76). In this series, the hydrophobicity of molecules increases, judging by the value of $\log P$ given in parentheses. For $\mathrm{APh}$ above $\mathrm{C}_{10}$, difficulties with the stability of the neutral solutions of the corrosion inhibitors are possible, since their hydrophobicity increases with a further increase in the alkyl length.

Note that octylphosphoric acid $(\log P=2.13)$ and dibutylphosphoric acid $(\log P=$ 2.2), let alone nonanoic acid $\mathrm{CH}_{3}\left(\mathrm{CH}_{2}\right)_{7} \mathrm{COOH}(\log P=3.43)$, are more hydrophobic than $\mathrm{APhC}_{8}(\log P=1.70)$. At $\mathrm{pH} 7.4$, the anions not only of $\mathrm{APhC}_{8}$ but also of $\mathrm{APhC}_{10}$ are hydrophilic ( $\log P=-1.37$ and -0.84 , respectively). Undoubtedly, a positive factor is that compounds with $\log P<3.0$ have a good passivating ability, as according to [23] they are less prone to bioaccumulation in organisms, especially in those living in water. This should reduce the environmental hazard of the metal passivation technology.

In addition, the well known synergism of the protective action of phosphonate complexones and zinc salts $[4,24,25]$ can be successfully transferred to the passivation of steels in aqueous solutions of even more hydrophilic alkyl carboxylates. For example, according to [26], $\mathrm{APhC}_{3}$ itself has weak protective properties in water containing only $60 \mathrm{mg} / 1 \mathrm{of} \mathrm{Cl}^{-}$and even at $C_{\mathrm{APh}}=150 \mathrm{mg} / \mathrm{l}$ the protection efficiency is $Z \leq 40 \%$. However, a composition of $75 \mathrm{mg} / 1 \mathrm{APhC}_{3}$ with $100 \mathrm{mg} / 1 \mathrm{Zn}^{2+}$ provides $Z=90 \%$, demonstrating the synergy in steel protection. As expected, the mixed corrosion inhibitor slows down both electrode reactions, and the protective film consists of the $\left[\mathrm{Fe}(\mathrm{III}) / \mathrm{Fe}(\mathrm{II}) / \mathrm{Zn}(\mathrm{II})-\mathrm{APhC}_{3}\right]$ complex, $\mathrm{Zn}(\mathrm{OH})_{2}$, as well as iron oxides and hydroxides.

As for higher $\mathrm{APh}$, they proved to be convenient objects of investigation for revealing the mechanism of formation of SAM and binding them to the surfaces of various metals. In this aspect, their hydrophobicity should also be considered as an important factor. Telegdi et al. [27] chose several phosphonates that were very different by the hydrocarbon part of the molecule for their study. These included $\mathrm{APhC}_{12}$, undecylenephosphonic acid (UPhA) containing a double bond in the $\mathrm{C}_{11}$ hydrocarbon chain, $\mathrm{APhC}_{16}$, a styrene-styrenephosphonic acid copolymer, and a phosphonic acid with a long fluorinated alkyl ( $\mathrm{APhF})$, whose composition, unfortunately, was not reported. Molecular films were applied from organic solvents (with $C_{\text {in }}=5$ or $50 \mathrm{mmol} / \mathrm{l}$ ) to carbon steels and stainless steels coated with an oxide layer. The exposures of steel samples were varied from 15 min to $48 \mathrm{~h}$. The modified surfaces were characterized by the contact angle of wetting with water $(\theta)$, using a dynamic surface tensiometer; the sample was immersed into water at a speed of $5 \mathrm{~mm} / \mathrm{min}$ to a depth of $8 \mathrm{~mm}$. Protection against corrosion of steels by the molecular films was evaluated by measuring the linear polarization resistance in a solution containing $\mathrm{NaCl}$ and $\mathrm{Na}_{2} \mathrm{SO}_{4}$.

The $\theta$ angles on the surfaces of steels after treatment with organic solutions of the investigated phosphonates and SAM formation were more than $95^{\circ}$. The highest values were observed in the case of $\mathrm{APhF}, \theta=118^{\circ}$ (for $316 \mathrm{LN}$ steel) and $129^{\circ}$ (for carbon steel). 
Treatment of steels with an UPhA solution did not impart hydrophobic properties to the surface of samples, and to cause polymerization of the adsorbed layer it was additionally illuminated with UV light $(\lambda=254 \mathrm{~nm})$ for $30 \mathrm{~min}$. The two-stage treatment increased the value of $\theta$, which indicates an increase in the compactness of the adsorption layer due to polymerization of UPhA on its double bond. Improvement in the hydrophobic properties of SAM can be achieved by increasing the time of its formation. In fact, an increase in the formation time from $4 \mathrm{~h}$ to $24 \mathrm{~h}$ for carbon steel increased $\theta$ from $83^{\circ}$ to $107^{\circ}$. A similar picture was observed on stainless steel 304 with $\mathrm{APhC}_{12}$, where $\theta$ increased from $95^{\circ}(15 \mathrm{~min})$ to $118^{\circ}(24 \mathrm{~h})$. However, an increase in the concentration of the reagent had little effect on $\theta$.

The results of the polarization resistance measurements showed that adsorption of $\mathrm{APhF}$ effectively protects carbon steel from corrosion, especially after the SAM formation for 4 or $24 \mathrm{~h}$ when the corrosion rate was less than $0.15 \mathrm{~mm} / \mathrm{year}$. On the contrary, the adsorption layers formed on the steel in the solution of copolymer studied, despite the presence of a large hydrophobic part in its molecule, were not resistant to the action of the corrosive aqueous solution and did not protect the steel from corrosion. The authors believe that the reason for this was the absence of a well-ordered layer structure.

Recently, in another work [28] the influence of the processing time of 304L stainless steel by ethanol solutions of $5.0 \mathrm{mM} \mathrm{APhC} 4, \mathrm{APhC}_{8}, \mathrm{APhC}_{10}$ or $\mathrm{APhC}_{16}$ was studied in order to determine the optimal conditions for the formation of SAM. It was found that the best results, judging from the cyclic voltammetry curves recorded in an aqueous solution containing $0.2 \mathrm{M} \mathrm{Na}_{2} \mathrm{SO}_{4}$ and $5 \mathrm{mM} \mathrm{K}_{4}\left[\mathrm{Fe}(\mathrm{CN})_{6}\right]$, were obtained at $8 \mathrm{~h}$ in $\mathrm{APh}$ solutions.

$\mathrm{APhC}_{18}$ attracted considerable interest due to the ability to form strong covalent bonds with oxides of various metals, as well as compact adsorption films due to van der Waals forces between the long alkyls of its molecules. Furthermore, having a molecule length of $2.2 \mathrm{~nm}, \mathrm{APhC}_{18}$ is well packed into self-organizing bilayers (SOB) [29]. They are formed inside concentrated solutions of $\mathrm{APh}$ and/or after slow evaporation of a solvent, for example ethanol; their thickness is $3.4-5.0 \mathrm{~nm}$, depending on the position in the multilayer film. Since $\mathrm{APhC}_{18}$ is a very simple linear phospholipid-like molecule, its two-layer structures can serve as simplified models of cell membranes. Binding of $\mathrm{APhC}_{18}$ bilayers to other simple phospholipid-like molecules with shorter alkyl chains, such as $\mathrm{APhC}_{14}$ or $\mathrm{APhC}_{8}$, can promote the formation of very simple mixed lipid bilayer systems. There is no doubt that similar SOB should have high passivating properties towards many metals and alloys.

Unfortunately, the author of this review failed to find any information about the results of direct corrosion tests of iron or low-carbon steels with a passive $\mathrm{APhC}_{18}$ film in the literature. However, papers where the adsorption layers of the APh were studied on stainless steels are known [27, 29-34].

Austenitic steel 316L (mass\%: 16-18 Cr, 10-14 Ni, 2.0-3.0 Mo, $\leq 0.03 \mathrm{C}, 2.0 \mathrm{Mn}$, $0.75 \mathrm{Si}, 0.045 \mathrm{P}, 0.03 \mathrm{~S}, 0.1 \mathrm{~N}$ ) has been studied most commonly. Corrosion protection of this steel is important from a practical point of view, since it is a widely known biomaterial 
used in medicine (cranial and orthopedic plates for fractures, dental implants, spinal rods and joint prostheses [36]). The surface properties 316L determine the advantages and shortcomings of this biomaterial, so has to be treated in order to improve the corrosion resistance and biocompatibility without losing the physico-mechanical properties of the steel.

A. Raman et al. [31] noted that, despite the extensive use of APh in industry, the features of the mechanism of their interaction with steels are not sufficiently understood. They used FTIR and XPS in the study of SAM formed in $1 \mathrm{mM}$ solutions of $\mathrm{APhC}_{18}$ or $\mathrm{APhC}_{8}$ in tetrahydrofuran (THF) on natural $316 \mathrm{~L}$ steel oxide at room temperature. It was found that $\mathrm{APhC}_{18}$ forms a well-ordered monomolecular layer that is not removed by washing with a pure solvent even if the steel is treated ultrasonically, but this washing allowed the removal of excess acid from the surface. The SAM remains stable even after the sample is washed in water or ethanol. FTIR spectra showed that $\mathrm{APhC}_{18}$ is covalently bound to the oxide surface due to the bidentate nature of the phosphonate ligand, which agrees with the results of the XPS analysis. The total surface coverage is confirmed by the measured value $\theta>105^{\circ}$, which is much higher than $\theta=45 \pm 3^{\circ}$ for the untreated surface, and by the surface image of the steel obtained by AFM. It is noted that such a formation of the SAM is different from the formation of phosphonate monolayers on other metal oxide substrates, such as $\mathrm{Ti}$ or $\mathrm{Si}$, which requires heating and prolonged exposure of a sample to a solution.

The authors of [32] proved that thermal treatment of 316L steel with a film applied from a $1.0 \mathrm{mM} \mathrm{APhC} 18$ solution in THF significantly strengthens the stability of adsorbed molecules on its surface. The treatment was carried out for $0.5-1.0 \mathrm{~h}$ at $100-120^{\circ} \mathrm{C}$. The AFM images obtained on the modified steel showed that the thermally treated films remained unchanged after washing with methanol, THF or water, but the films obtained without heat treatment changed significantly. Contacts with water also show that the hydrophobicity of the thermally treated films does not decrease after keeping the samples for $3 \mathrm{~h}$ in a water stream, while an untreated film becomes increasingly hydrophilic. IR spectra obtained with treated and untreated $\mathrm{APhC}_{18}$ films after contact with water and THF show that the remaining film retains its original crystallinity. It should be noted that thermal treatment of samples with an APh film does not greatly increase $\theta$, i.e., from 90 to $97^{\circ}$, but retains its hydrophobicity for at least $3 \mathrm{~h}$ at the level of $\theta=90-92^{\circ}$. Without it, hydrophobicity rapidly decreases to $\theta=75-78^{\circ}$. The authors explain the increase in the stability of the $\mathrm{APhC}_{18}$ film after thermal treatment in that its molecules are first physically adsorbed, so they are weakly bound to the surface by the hydrogen bond. Although these films are not monolayers, heating removes water molecules, which leads to the formation of strong mono- or mixed mono/bidentate bonds of $\mathrm{APhC}_{18}$ molecules with the surface.

Recently M. Kosian et al. [35] carried out more detailed studies of the structure and thermal stability of SAMs formed by $\mathrm{APhC}_{3}-\mathrm{APhC}_{18}$ on $316 \mathrm{~L}$ steel. The studies were carried out in acidic $(\mathrm{pH} 3)$, basic $(\mathrm{pH} 11)$ media, in neutral saline $(10 \mathrm{mM}$ phosphate buffer with $\mathrm{pH} 7.4)$, and with dry heating $\left(120^{\circ}\right)$. All the APhs formed SAMs with 
hydrophobic properties, but they were well ordered in the case of $\mathrm{APhC}_{12-18}$ only. This is indicated by the results of measurements of static $\theta$, XPS, AFM, and reflective absorption IRS. A long-term stability study showed the excellent stability of the SAMs formed by $\mathrm{APhC}_{12-18}$ in up to 30 days in acidic, neutral and saline solutions and in up to 7 days in dry heating mode. Partial breakdown of the monolayer was observed in the alkaline medium, especially for shorter chain lengths.

However, not all researchers share the opinion that SAMs formed by $\mathrm{APhC}_{12}$ on $316 \mathrm{~L}$ steel have high stability in the physiological environment. For example, Kaufman et al. [34] noticed that steel samples covered by this $\operatorname{SAM}\left(\theta=101.6^{\circ}\right)$ immersed in a physiological solution of TBS with $\mathrm{pH} 7.4$ at $t=37^{\circ} \mathrm{C}$ for 28 days were inferior in the stability of the SAM formed in $24 \mathrm{~h}$ by a $1 \mathrm{mM}$ solution of 11-phosphonodecanecarboxylic acid $\mathrm{HOOC}\left(\mathrm{CH}_{2}\right)_{10} \mathrm{PO}(\mathrm{OH})_{2}$ in THF $\left(\theta=102.5^{\circ}\right)$. The $\theta$, XPS and AFM measurements showed significant desorption of phosphonic acid molecules from stainless steel surfaces in 1-7 days after immersion in TBS followed by slow desorption during the remaining days. The authors believe that this desorption is due to the hydrolysis of phosphonic acid molecules. Although the SAM formed by APh containing a terminal $\mathrm{COOH}$ group in the alkyl, which is larger than $\mathrm{CH}_{3}$, it has a less dense packing of the monolayer than $\mathrm{APhC}_{12}$, but it is more stable than the $\mathrm{SAM}$ with $\mathrm{APhC}_{12}$. This increased stability can be due to hydrogen bonds between the chains. These interchain hydrogen bonds can serve as a barrier that prevents water molecules from reaching and splitting the phosphonate head group. Another mechanism of increased stability can involve a polar or hydrogen bond of water molecules with the head group. The higher affinity of water molecules to $\mathrm{COOH}$ groups may prevent the water molecules from reaching the head groups of phosphonates on the surface of the metal oxide.

In [34], the effect of multivalent binding of bisphosphonic acids to the surface of steel on the stability of the monolayer was also studied and the authors concluded that it apparently allows improving the stability of the monolayer, although further work is needed to combine several points of their fixation on the steel surface with simultaneous increasing of the packing density of the attached alkyl chains. The results obtained indicate the usefulness of phosphonic acid monolayers for many applications, even under rather harsh conditions, especially in light of their already known effects of inhibiting the corrosion of metals.

Lecollinet et al. [37] revealed the differences in the adsorption on $\mathrm{APh}$ and 1hydroxyalkylene-1,1- and other gem-bisphosphonic acids $\left(\mathrm{GBPh}_{x}\right)$ on 316L steel. They correctly noted that $\mathrm{GBPh}_{x}$ are easier in use because they readily form SAMs from aqueous solutions, whereas higher APhs usually require an organic solvent. However, two adjacent phosphonic groups increase the surface area of a molecule and thereby reduce the packing density of side chains in monolayers. To assess the importance of chemical fragments and structure of molecules, the authors studied the formation of SAM on steel by $\mathrm{APhC}_{18}$ and by five gem-bisphosphonates containing: a linear alkyl $\left(\mathrm{GBPhC}_{16}\right)$, a branched alkyl $\left(\mathrm{GBPhC}_{20}\right)$, a linear perfluorinated alkyl $\left(\mathrm{GBPhC}_{10} \mathrm{~F}_{17}\right), \mathrm{GBPhC}_{20} \mathrm{~F}_{28}$ with a branched chain 
perfluoropolyether a double linear perfluorinated alkyl chain of [(3,5-(3,5-di-(perfluorooctyl)-phenyl-hydroxymethylene]bisphosphonic acid. It was found that after steel treatment in $1 \mathrm{mmol} / \mathrm{l}$ solutions of the reagents in acetone (THF was used for $\mathrm{APhC}_{18}$ ), the value of $\theta$, i.e., hydrophobicity of the steel surface, increased in the series: $\mathrm{GBPhC}_{16}$ $\left(96^{\circ}\right)<\operatorname{GBPhC}_{20}\left(98^{\circ}\right)<\mathrm{GBPhC}_{10} \mathrm{~F}_{17}\left(101^{\circ}\right)<\mathrm{APhC}_{18}\left(105^{\circ}\right)<\mathrm{GBPhC}_{20} \mathrm{~F}_{28}\left(106^{\circ}\right)$. In addition, $\mathrm{GBPhC}_{20} \mathrm{~F}_{28}$ not only hydrophobized steel from organic solutions better than the other reagents, but also provided $\theta=106^{\circ}$ even when applied from an aqueous solution. This hydrophobic film remained stable even after prolonged exposure of the steel sample in pure water at $t=50^{\circ}$. The authors noted that structure of the $\mathrm{GBPhC}_{16}$ molecule is very close to that of $\mathrm{APhC}_{18}$, but the value of $\theta$ for steel treated with $\mathrm{APhC}_{18}$ is much larger. Because of its structure, the layer of $\mathrm{GBPhC}_{16}$ molecules is somewhat less homogeneous or densely packed, which limits the hydrophobicity of a surface with the SAM.

The $\mathrm{GBPhC}_{20} \mathrm{~F}_{28}$ molecule incorporating a bisphosphonate moiety has characteristics meeting the requirements of industrial applications. It is soluble in water and can make the surface of stainless steel or Ti much more hydrophobic and lipophobic than PTFE in a few minutes. The SAM that it forms can resist severe conditions, such as prolonged immersion in water, various $\mathrm{pH}$ of the medium, and autoclaving. All this creates good prospects for its application for the protection of metal surfaces from corrosion and contamination.

Aluminum and its alloys. Despite their wide application in various industries and the high affinity of Al to oxygen, due to which it is almost always coated with a protective oxide film, it has long been known that even artificial oxidation very often does not save aluminum alloys from corrosion. The use of organic corrosion inhibitors, mainly salts of carboxylic acids, for passivation of $\mathrm{Al}$ and its alloys, has over half a century long history $[4,38]$. However, studies of the adsorption of phosphonic acids on Al began much later when their salts or complex compounds were not only widely investigated, but also used to protect steel from corrosion and salt deposits [1-4].

It is not surprising that the first studies of adsorption on $\mathrm{Al}$ and its alloys were carried out with polybasic phosphonic acids (complexons), which are usually very hydrophilic and have been studied in $[39,40]$ as inhibitors of hydration (IG) of adhesion bonds rather than Al corrosion. However, already Ramsier et al. [40], who apparently were apparently the first to study the adsorption of Al-methylphosphonic acid $\left(\mathrm{APhC}_{1}\right)$, came to the conclusion that it enters a condensation reaction with $\mathrm{OH}$ groups on the surface to form a symmetrical $\mathrm{PO}_{3}$ structure, and water as a reaction side product. The absence of a spectral structure near $3610 \mathrm{~cm}^{-1}$ was considered as evidence that APS1 actively displaces adsorbed OH groups and isolates the open surface centers.

Stratmann et al. [41] believe that the behavior of $\mathrm{APhC}_{1}$ should little differ from that of $\mathrm{APh}$ with a large number of $\mathrm{CH}_{2}$ groups in the alkyl. To study the time scale of the process of $\mathrm{APh}$ self-organization, the time required to cover the surface completely is an important parameter. To determine it, samples of $\mathrm{Al}(99.999 \%)$ and $\mathrm{AlMg} 1$ alloy (mass\%: $0.76 \mathrm{Mg}, 0.29 \mathrm{Fe}, 0.08 \mathrm{Si}$ ) were placed for $1-120 \mathrm{~s}$ into an organic solvent containing an $\mathrm{APh}$, then the adsorption layer thus obtained was analyzed by estimating the peak 
amplitudes for P KLL and O KLL in Auger spectra. The results of the study have shown that APhs are capable of creating SAMs; the surface coating is completed within about $2 \mathrm{~min}$, but the self-organization of the films takes over 3 days. This is observed not only on $\mathrm{Al}$ but also on inhomogeneous $\mathrm{AlMg} 1$ surfaces.

An important role in the interest to SAMs on $\mathrm{Al}$ and its alloys belongs to the results obtained in [42]. Its authors used IRS, ellipsometry, and measurements of the $\theta$ angle to study SAM on natural $\mathrm{Al}$ oxide formed by three APhs: $\mathrm{CF}_{3}\left(\mathrm{CF}_{2}\right)_{7}\left(\mathrm{CH}_{2}\right)_{11} \mathrm{PO}_{3} \mathrm{H}_{2}$ $\left(\mathrm{APhC}_{19} \mathrm{~F}_{17}\right) ; \mathrm{APhC}_{16}$ and $\mathrm{APhC}_{22}$. The films were applied from 0.1 mass\% solutions of $\mathrm{APhC}_{19} \mathrm{~F}_{17}$ or $\mathrm{APhC}_{16}$ in ethanol, and $\mathrm{APhC}_{22}$ in THF. These compounds showed significant differences in the film structure and formation kinetics. Interestingly, the methylene segment of the semifluorinated $\mathrm{APhC}_{19} \mathrm{~F}_{17} \mathrm{SAM}$ never reached an ordered state even after long assembly times. This contrasts with the ordered chains in the equilibrium films of $\mathrm{APhC}_{16}$ and $\mathrm{APhC}_{22}$. The authors explained this by the steric effect of the fluorocarbon segment and the head group of phosphonic acid, since $\mathrm{APhC}_{19} \mathrm{~F}_{17}$ is an amphiphile in which the bulky head and tail groups interfere with the ordering of the hydrocarbon segment. The presence of negative peaks in all IR spectra of phosphonic acid monolayers due to the loss of $\mathrm{Al}-\mathrm{OH}$ groups confirms a condensation reaction between the acids and surface hydroxyls to form aluminophosphonate salts.

As for kinetics, $\mathrm{APhC}_{19} \mathrm{~F}_{17}$ approaches the equilibrium of the film structure much more rapidly than $\mathrm{APh}$. In it, the ellipsometric thickness of the film, the static angle $\theta$ of water drops and hexadecane, as well as the IR frequencies and intense bands of the methylene band, reach equilibrium values in 5-10 minutes of exposure of the $\mathrm{Al}$ substrate in 0.1 mass $\% \mathrm{APhC}_{19} \mathrm{~F}_{17}$ solution. The behavior of $\mathrm{APhC}_{16}$ and $\mathrm{APhC}_{22}$ films is different. The IR frequencies in the methylene band of both films on $\mathrm{Al}$ oxide decrease to values indicative of ordered chains in $5 \mathrm{~min}$ in the case of $\mathrm{APhC}_{22}$ but in several days in the case of $\mathrm{APhC}_{16}$. However, the intensity of the bands decreases for several days in both cases. The $\theta$ angle of the APh film changes, as does the IR intensity of the methylene band. The thickness measured ellipsometrically for both $\mathrm{APhC}_{16}$ and $\mathrm{APhC}_{22}$ requires several hours to reach equilibrium values. The authors suggested that the accelerated film formation exhibited by $\mathrm{APhC}_{19} \mathrm{~F}_{17}$ can be associated with chain adherence and solubility to the extent that it can be self-organized as islands of almost vertically oriented chains that are filled as the coverage increases. $\mathrm{APhC}_{22}$ can also precipitate in the form of islands, but the formation of a film from $\mathrm{APhC}_{16}$ probably includes initially disordered chains with higher incidence angles. They are ordered and reoriented as the film is assembled.

In view of the miniaturization of electronics and development of micro/nanoelectromechanical systems over the past decade, the SAMs on Al surfaces are the subject of intense research related to the prospects of their wide application. Since even lower APhs can form strong bonds with oxidized Al, chemical compounds of this class attract much attention of researchers.

E. Hoque et al. [43] studied SAMs on Al films obtained by physical vapor deposition on $\mathrm{Si}$. To form SAMs at room temperature, they used 0.1 mass $\% \mathrm{APhC}_{10} \mathrm{~F}_{17}, \mathrm{APhC}_{10}$ and 
$\mathrm{APhC}_{18}$ solutions in ethanol, in which the samples were immersed for 20 hours. XPS analysis confirmed the presence of $\mathrm{APhC}_{10} \mathrm{~F}_{17}, \mathrm{APhC}_{10}$ and $\mathrm{APhC}_{18}$ molecules on the $\mathrm{Al} / \mathrm{Si}$ surface. The static angle $\theta$ of a drop of water was usually $>130^{\circ}$ for $\mathrm{APhC}_{10} \mathrm{~F}_{17}$, while $\mathrm{APhC}_{10}$ and $\mathrm{APhC}_{18}$ provided $\theta>125^{\circ}$, which indicates strong hydrophobization of the $\mathrm{Al} / \mathrm{Si}$ surface. In the following work [44], studies were carried out on oxidized $\mathrm{Al}$, and $\mathrm{APhC}_{8}$ was studied instead of $\mathrm{APhC}_{10} \mathrm{~F}_{17}$. After treatment of the sample surface by a $0.1 \%$ $\mathrm{APhC}_{8}$ solution in THF, $\theta$ was $<105^{\circ}$, although in the case of similar treatment with $\mathrm{APhC}_{10}$ or $\mathrm{APhC}_{18}$ solution with the same concentration, $\theta$ was $>115^{\circ}$. In addition, the $\mathrm{SAM}$ formed by $\mathrm{APhC}_{18}$ gave the lowest coefficient of friction on $\mathrm{Al}$, while the surface itself had the highest one.

In the same year, it was reported that higher $\mathrm{APh}$, e.g., $\mathrm{APhC}_{14}$ [45], can be used to obtain a superhydrophobic surface on $\mathrm{Al}$ or its alloy, $\mathrm{AlMg} 1$. To do so, it was recommended to perform their anodization in an aqueous solution of $\mathrm{H}_{2} \mathrm{SO}_{4}$ at elevated temperature and current density, followed by a chemical modification of the surface. It was conducted by immersing the oxidized samples for $12 \mathrm{~h}$ in 0.1 mass $\%$ water-ethanol $(1: 1)$ $\mathrm{APhC}_{14}$ solution and completed by quenching at $120^{\circ} \mathrm{C}$ for $1 \mathrm{~h}$. Wetting was characterized by dynamic measurements of the contact angles (advancing angle $\theta_{\mathrm{a}}$, receding angle $\theta_{\mathrm{r}}$ ) on 3-5 areas on each sample. According to these measurements, the angles were in the range $150^{\circ}-155^{\circ}$ with a predominantly insignificant hysteresis $\theta_{\mathrm{a}}-\theta_{\mathrm{r}}$. The state of the electrodes was examined by electrochemical impedance spectroscopy (EIS) to obtain typical characteristics that were compared for superhydrophobic and anodized-only surfaces. The EIS results made it possible to conclude that the initial nanoporosity of the oxidized surface changed upon chemical modification by various variants. However, samples modified with $\mathrm{APhC}_{14}$ generally became completely hydrophilic after $29 \mathrm{~h}$ in phosphate buffer, whereas those treated in a 2 vol.\% perfluoroalkyltriethoxysilane solution in tertbutyl methyl ether $(3 \mathrm{~h})$, hydrophobicity degradation was nearly not observed.

Thus, the hydrophilic anodized surface of Al with a micro-roughness can be successfully hydrophobized by treatment with solutions of carboxylic or phosphonic acids with a long alkyl or by various silanes, among which the most stabile hydrophobicity is provided by perfluoroalkyl triethoxysilanes.

A comparison of the properties of $\mathrm{SAMs}$ formed in solutions of $\mathrm{APhC}_{8}, \mathrm{APhC}_{10}$, $\mathrm{APhC}_{18}, \mathrm{APhC}_{10} \mathrm{~F}_{17}$, or perfluorodecyldimethylchlorosilane $\mathrm{CF}_{3}\left(\mathrm{CF}_{2}\right)_{7}\left(\mathrm{CH}_{3}\right)_{2} \mathrm{SiCl}$ (PFMS) on the surface of $\mathrm{Al}$ deposited on Si was continued in Ref. [46]. $n$-Hexane or ethanol were used as the solvents. A common property of the compounds studied is their ability to undergo condensation with hydroxyls on Al surface $(-\mathrm{Al}-\mathrm{OH})$. For APhs, this is described by the scheme:

$$
\mathrm{R}-\mathrm{PO}(\mathrm{OH})_{2}+-\mathrm{Al}-\mathrm{OH} \rightarrow \mathrm{R}-(\mathrm{OH}) \mathrm{OP}-\mathrm{O}-\mathrm{Al}-+\mathrm{H}_{2} \mathrm{O}
$$

The silanol $(-\mathrm{Si}-\mathrm{OH})$ formed after silane hydrolysis reacts similarly:

$$
\mathrm{R}_{3}-\mathrm{Si}-\mathrm{OH}+-\mathrm{Al}-\mathrm{OH} \rightarrow \mathrm{R}_{3}-\mathrm{Si}-\mathrm{O}-\mathrm{Al}+\mathrm{H}_{2} \mathrm{O}
$$


However, the low durability of most SAMs under ambient or more drastic conditions makes it difficult to use them in practice. Introduction of fluorocarbon groups into the alkyl chain of a silane or phosphonic acid molecule makes the SAMs more stable than those composed of similar molecules with hydrocarbon chains.

SAMs on Al were studied by AFM in order to reach a better understanding of their micro- and nanotribological properties. The adhesion forces for PFMS/Al SAMs were found to be lower than those of bare $\mathrm{Al} / \mathrm{Si}$, but the coefficients of friction were comparable for both. XPS analysis revealed the presence of molecules with the corresponding alkyl chains in $\mathrm{SAMs}$ formed on $\mathrm{Al}$ in PFMS, $\mathrm{APhC}_{18}, \mathrm{APhC}_{10}, \mathrm{APhC}_{8}$ and $\mathrm{APhC}_{10} \mathrm{~F}_{17}$ solutions. The measurement of static $\theta$ of a drop of pure water on $\mathrm{Al}$ shows that all the SAMs are hydrophobic, giving $\theta>130^{\circ}$ for $\mathrm{APhC}_{18}, \mathrm{APhC}_{10} \mathrm{~F}_{17}$, or PFMS and $>125^{\circ}$ for $\mathrm{APhC}_{10}$ and $\mathrm{APhC}_{8}$.

Attention should be paid to the role of hydroxyl groups on the surface of Al oxide that is almost always present on this metal and its alloys. In fact, the effect of atmospheric moisture on the chemical composition of the surface of magnetron-sputtered Al (MS-Al) is characterized by addition of hydroxyls to its oxide layer with simultaneous adsorption of volatile carbonaceous contaminants from the air [47]. It is difficult to form a well-ordered SAM of stearic acid (SA) on such a surface, and the authors proposed to pre-treat it for 13 min in oxygen plasma. It was found that after this, ordering of SAMs formed by SA occurs not only faster but is also better preserved in time. It is possible that this kind of cleaning of oxidized Al surface would also be useful in the formation of SAMs by alkylphosphonic acids.

In this respect, attention should be paid to an excellent study of the resistance of SAMs on MS-Al to the impact of acidic and alkaline aqueous solutions performed by measuring the dynamic contact angle $\Delta \theta=\theta_{\mathrm{a}}-\theta_{\mathrm{r}}$ [48]. Here, $\theta_{\mathrm{a}}$ is the advancing angle between the liquid and the solid that is created during the wetting process, in contrast to the static contact angle measured without changing the contact area between them. The value of $\theta_{\mathrm{r}}$ is the contact angle of receding between a liquid and a solid, the wetting of which is already decreasing. In this method, the force $F$ is measured, from which $\theta$ can be calculated. A small plate of a solid material attached to the arm of the force meter is immersed vertically into the liquid, and the force acting on the liquid is measured with high sensitivity. It is related to $\theta$ by the following equation:

$$
\cos \theta=\left(F-F_{\mathrm{b}}\right) \cdot l \cdot \sigma,
$$

where $F$ is the total force measured by the force meter, $F_{\mathrm{b}}$ is the buoyancy force due to which the solid sample displaces the liquid, $l$ is the wetted length of the sample, and $\sigma$ is the surface tension of the liquid. The main advantage of this method is that the measured data are averaged over the wetted length, i.e., it gives a more accurate average value of $\theta$ and is more objective than the static drop method. Disadvantages of the method include a more complex experiment, the sample must be made with a uniform cross-section in the 
direction of immersion, and the wetted length should be measured with good accuracy. The method is applicable only in the case of complete identity of both sides of the sample.

Comparison of $\theta_{\mathrm{a}}$ and $\theta_{\mathrm{r}}$ for SAMs formed by carboxylic and phosphonic acids on MS-Al, measured in water with $\mathrm{pH} 7$, showed that the most stable $\theta_{\mathrm{a}}=120^{\circ}$ was obtained in the case of the $\mathrm{APh}$ with the longest alkyl, i.e., $\mathrm{APhC}_{18}$. It nearly did not change, decreasing to $118^{\circ}$ after 10 cycles. This indicates the stability of the SAM in water over the entire immersion time studied. The surface second in stability was provided by the SAM formed on MS-Al by nonadecanoic acid, $\mathrm{C}_{18} \mathrm{H}_{37} \mathrm{COOH}$ (NDA), where the $\theta_{\mathrm{a}}$ angle decreased from $121^{\circ}$ to $100^{\circ}$ in $1 \mathrm{~h}$, indicating a gradual degradation of the monolayer. The $\theta_{\mathrm{r}}$ values measured for the samples with $\mathrm{APhC}_{18}$-formed SAM were lower than $\theta_{\mathrm{a}}$ and followed similar trends, while those of the SAMs formed by carboxylic acids were much lower than the approaching angles $\theta_{\mathrm{a}}$, without any differences between the samples based on $\mathrm{C}_{4} \mathrm{H}_{9} \mathrm{COOH}$ and $\mathrm{C}_{10} \mathrm{H}_{21} \mathrm{COOH}$.

Since the SAMs formed on MS-Al by carboxylic and phosphonic acids with $\mathrm{C}_{18}$ alkyl are relatively stable in water, more corrosive solutions with $\mathrm{pH} 1-11$ were used in further tests of the stability of these SAMs. The initial $\theta_{\mathrm{a}}$ of $\mathrm{APhC}_{18}$-based SAM on MS-Al was in the range of $120-124^{\circ}$ in all the solutions, except for the solution with $\mathrm{pH} 11$ where SAM desorption was fast. In solutions with $\mathrm{pH} 1-10, \theta_{\mathrm{a}}$ decreased to values between 117 and $123^{\circ}$ after 10 cycles, indicating improved stability over NDA. Using the fifth immersion cycle to rank the relative degradation rate of the monolayers, it was found that the monolayer is most resistant to degradation in the solution with $\mathrm{pH} 3$. The authors concluded that the acids with short or intermediate alkyl chain lengths are unstable in water with neutral $\mathrm{pH}$, whereas molecules with the longest alkyl chains $\left(\mathrm{C}_{18}\right)$ show considerably greater stability in neutral, high and low $\mathrm{pH}$ solutions. The packing density inferred from the $\theta$ and $\Delta \theta$ values suggests the NDA monolayer to be slightly worse packed than that of $\mathrm{APhC}_{18}$. This is consistent with related friction force microscopy and infrared reflection absorption spectroscopy findings published elsewhere $[49,50]$. For example, DeRouz et al. later confirmed [50] that perfluorodecanoic acid $\mathrm{CF}_{3}\left(\mathrm{CF}_{2}\right)_{8} \mathrm{COOH}$ (PFDA) forms SAMs on Al that gives high hydrophobicity to its surface $\left(\theta>125^{\circ}\right)$ and has higher stability than that of PFMClS, but lower than those of $\mathrm{APhF}_{19} \mathrm{C}_{10}$ or $\mathrm{APhC}_{18}$.

It should be noted that $\mathrm{APhC}_{18}(\log P=7.01)$ is less hydrophobic than SA $(\log P=8.23)$ and even more so NDA $(\log P=8.75)$. However, its adsorption creates a hydrophobic SAM on oxidized Al that is more stable than that formed by carboxylic acids. The authors seem to be right to state that this is due to stronger binding of the phosphonic head group to MS-Al than by binding to the carboxyl group. In view of this, to understand the mechanism of the formation of SAMs by $\mathrm{APhC}_{18}$ and to increase their stability in water, it is very important to carry out adsorption studies on different aluminum oxide surfaces.

It is this goal that the authors of [51] have set themselves. They studied the adsorption of $\mathrm{APhC}_{18}$ on $\mathrm{Al}_{2} \mathrm{O}_{3}$ single crystal surfaces (0001) and (1102), which was compared with 
its adsorption on passive films of amorphous Al oxide on this metal and on those physically deposited on $\mathrm{Au}$ from vapor phase (PVD). SAMs were formed in an ethanolic solution of $\mathrm{APhC}_{18}$ and were studied using $\mathrm{AFM}$, diffuse reflection FTIR, polarizationmodulated IRS reflection (PM-IRRAS), and by measurement of the $\theta$ angle.

The SAMs were formed in an ethanolic solution of $\mathrm{APhC}_{18}$ and studied using $\mathrm{AFM}$, diffuse reflection FTIR, polarization-modulated IRS reflection (PM-IRRAS), and measurement of the $\theta$ angle. The SAMs formed by $\mathrm{APhC}_{18}$ showed high stability in aqueous media on the surfaces of single crystal (1102) or amorphous $\mathrm{Al}_{2} \mathrm{O}_{3}$. However, on the surface of $\mathrm{Al}_{2} \mathrm{O}_{3}(0001)$, the adsorbed $\mathrm{APhC}_{18}$ monolayers were replaced by adsorption of interfacial water with intermediate formation of micelles. The authors explained the different stability of SAMs in aqueous media "by variation of interfacial binding states ranging from ionic interactions between phosphonate groups and the positively charged hydrolyzed oxide surface to directed coordination bonds between the phosphonate group and Al ions".

Despite the fact that the formation of SAMs by APhs on Al or its oxide was extensively studied, many methods allow only indirect observation of changes in the surface state during adsorption. Studies carried out in situ are of great interest to reveal the mechanism of formation of the adsorption layer. The authors of [52], using exactly such methods (AFM and ellipsometry), demonstrated with $\mathrm{APhC}_{8}$ as an example that the adsorption of APh on Al oxide occurs with formation and growth of three-dimensional islands and involves three stages. First, an increase in the number of islands occurs, followed by filling of the gaps between them. In the third stage, within the adsorption time frame measured, the islands grow in size but not in number. According to the authors, it is close to the behavior of films analyzed by ex situ methods.

Later, Hauffman et al. [53, 54] used one more in situ method, odd random phase multisine (ORP) EIS, for studying the adsorption of ethanol and $\mathrm{APhC}_{8}$ from an ethanol solution on $\mathrm{Al}$ oxide. Its difference from the classical EIS lies in the possibility of calculating the elements of an equivalent circuit for non-steady-state measurements.

They showed that the condensation reaction that can occur between alcohol or APh molecules and surface hydroxyls promotes the displacement of water near the hydrophilic surface of the oxide, while the APh molecules bind to it ionically. The authors came to the important conclusion that ethanol as a solvent is not suitable for the formation of stable layers of organic acids on the surface. The reason for this conclusion is that water diffusion into the solvent bulk is slow, thus a dangerous local environment is formed on the oxide surface. In the opinion of the authors, ORP EIS is an ideal method that makes it possible not only to investigate the dynamics of the adsorption of very thin films in situ, but also to understand what happens with the adsorbent itself.

The role of the APh solvent in the formation of SAMs is also discussed by the authors of Ref. [55] who studied it in the adsorption of $\mathrm{APhC}_{14}$ (from $5 \mathrm{mM}$ water-ethanol solution) on the surface of 2024 aluminium alloy (mass\%: $3.8-4.9 \mathrm{Cu}, 1.2-1.8 \mathrm{Mg}, 0.3-$ $0.9 \mathrm{Mn}, 0.5 \mathrm{Fe}, 0.5 \mathrm{Si}, 0.5$ other elements). The COMs were formed from one of the 
following solutions: $\mathrm{A}$ - absolute ethanol, $\mathrm{B}$ - a mixture of water with ethanol $(2: 8 \mathrm{v} / \mathrm{v})$, $\mathrm{C}$ - same mixture $(4: 6 \mathrm{v} / \mathrm{v})$. The anticorrosive properties of SAMs on 2024 alloy were studied in $0.1 \mathrm{M} \mathrm{H}_{2} \mathrm{SO}_{4}$ and measured by potentiodynamic polarization and EIS, while its composition and structure were determined by means of Auger electron (AES) and FTIR spectroscopy and $\mathrm{AFM}$. It was shown that $\mathrm{APhC}_{14}$ molecules were strongly adsorbed on the surface of 2024 alloy, and the packing density of the SAM decreased with increasing content of absolute ethanol in the solution. The results of electrochemical studies and observation of changes in morphology by means of AFM indicate that the optimal modification occurs within $4 \mathrm{~h}$ : such SAMs provide the maximum inhibition efficiency $(Z=64.03,84.53$ and $91.41 \%$ for the SAMs formed in solvents A, B and C, respectively). This shows that the higher the water content in the water-ethanol solution, the higher the protective effect of the SAM. Comparison of the FTIR spectra of the samples with SAMs formed in solutions $\mathrm{A}, \mathrm{B}$ and $\mathrm{C}$ indicates that the intensity of all the characteristic peaks of adsorbed $\mathrm{APhC}_{14}$ molecules gradually increases with increasing water volume from 0 to $20 \%$, and then to $40 \%$. The effect of water content in $\mathrm{APhC}_{14}$ solutions on $\mathrm{SAM}$ formation is related to the hydration reaction of the metal surface. These results are consistent with the conclusion drawn from electrochemical studies on the utility of adding water to the alcohol solution of $\mathrm{APC}_{14}$, since in this case hydration of the alloy surface is enhanced, which promotes the chemical adsorption of $\mathrm{APh}$ to form more $\mathrm{P}-\mathrm{O}-\mathrm{Al}$ bonds.

Sato et al. [56] investigated the formation of adsorption layers on pure $\mathrm{Al}$ from a $2 \%$ $\mathrm{APhC}_{14}$ solution in ethanol using low voltage SEM (less than $1 \mathrm{kV}$ ), AFM, XPS and by measuring the $\theta$ angles by the static and dynamic methods. They showed that in the first case, the value of $\theta=105^{\circ}$ is established in 2 days of $\mathrm{Al}$ immersion in the passivating solution. The dynamic angles $\theta_{\mathrm{a}}$ and $\theta_{\mathrm{r}}$ continue to grow and reach a limiting value in 3 days $\left(110^{\circ}\right.$ and $85^{\circ}$, respectively). AFM observations suggest that the bilayers of $\mathrm{APhC}_{14}$ are deposited on the substrate in the form of a multilayer film. The authors concluded that a uniform SAM is not always formed readily on an oxidized Al surface.

It is generally recognized that the chemistry of the surface of metal oxides plays an important role in $\mathrm{APh}$ adsorption. In this respect, interesting results were obtained by German researchers [57] who studied the kinetics of $\mathrm{APhC}_{18}$ adsorption on the surface of Al covered with natural oxide, which was modified by water plasma and argon plasma. The adsorption of $\mathrm{APhC}_{18}$ was evaluated using the quartz crystal microbalance (QCM) method on different Al oxide films. Measurements performed in situ by FTIR in combination with ex situ XPS showed that treatment with aqueous plasma increases the surface density of hydroxyls in the surface layer of the oxide, and subsequent treatment with argon plasma converts the hydroxyls into oxides. A strong dependence of the adsorption kinetics on the hydroxyl surface density on oxide-coated Al surfaces was found. With an increase in the surface density of the hydroxyls, the adsorption kinetics can be accelerated, which can be explained by the adsorption of $\mathrm{APhC}_{18}$ through surface hydrogen bonds even prior to the condensation reaction, leading ultimately to strong adsorption of the phosphonate. 
Attention should be paid to the results of a study of SAMs formed by atomic layer deposition (ALD) on the surfaces of $\mathrm{Al}$ and $\mathrm{Hf}$ oxides from $\mathrm{APhC}_{18}$ or $\mathrm{APhC}_{12} \mathrm{~F}_{17}$ solutions [58]. The well known Langmuir-Blodgett method, which makes it possible to obtain homogeneous SAMs, is the most reproducible, therefore studies on the stability of monolayers mainly used this method. All films deposited on a $\mathrm{Al}$ or $\mathrm{Hf}$ oxide surface were characterized by spectroscopic ellipsometry, measurements of the water wetting angle $\theta$, XPS and AFM. XPS data convincingly proved the covalent bonding of phosphonates with both substrates. The SAMs formed on $\mathrm{Al}_{2} \mathrm{O}_{3}$ and $\mathrm{HfO}_{2}$ are stable in water. The SAMs formed by $\mathrm{APS}_{12} \mathrm{~F}_{17}$ on $\mathrm{HfO}_{2}$ are the most stable among the ultrathin coatings in tests carried out at room temperature in water or phosphate buffer $(\mathrm{PhB})$. Similar coatings based on octadecyltrichlorosilane on $\mathrm{SiO}_{2}$ are unstable in $\mathrm{PhB}$. The authors consider that phosphonate SAMs have better prospects for use as coatings on (bio)molecular sensitive devices that use ALD and require longer-term stability in aqueous media.

Telegdi et al. [59], explaining the widespread recognition of SAMs formed by perfluoroalkylphosphonic acids usually containing $\mathrm{C}_{7}$ or $\mathrm{C}_{8}$, noted that such ultrathin coatings are better than similar APhs with hydrocarbon or silicone tails. With the example of $\mathrm{APhC}_{8} \mathrm{~F}_{10}$, they showed the ability of $\mathrm{APhF}$ to prevent not only general but also local corrosion of an $\mathrm{Al}$ alloy in $0.1 \mathrm{M} \mathrm{NaCl}$. Measurements of the dynamic contact angles of water on the alloy surface revealed a positive effect of the formation time of the SAM, i.e., the exposure time of a sample in a methanolic solution, on its stability in a corrosive medium. An increase in the concentration of APS8F10 in methanol from $5 \mathrm{mM}$ to $50 \mathrm{mM}$ also contributed to the formation of a more compact SAM.

Considering the prospects of practical application of SAMs formed on Al or its alloys by $\mathrm{APh}$, their use as promoters of adhesion of polymer coatings should to briefly mentioned first of all. As long ago as in the late 1990s [60], German researchers who were developing the Stratmann's ideas about replacing chromate pre-passivation of metals by SAMs formed by a surfactant with two reaction groups, investigated the possibility of using different chemical compounds of general formula $\mathrm{C}_{18} \mathrm{H}_{37} \mathrm{X}$, which included some phosphonic acids, as adhesion promoters of polymer coatings on AMg1 alloy. They showed that surfactants containing a phosphonic head group and a group capable of reacting with a polymer are able to be strongly adsorbed on the Al surface. In this case, according to the results of a FTIR surface study, oriented layers are formed, while the second ("terminal") group provides chemical interactions with the organic coating. This is demonstrated by model reactions with isocyanates and confirmed by adhesion and corrosion tests. The authors concluded that the effect of bifunctional surfactants is equivalent to chromated surfaces due to corrosion inhibition and improvement of the adhesion strength of the polymer coating.

These studies were continued in the past decade. For example, in [61], amino- $\mathrm{APhC}_{3}$ was studied as a short-chain bifunctional adhesion promoter for an epoxy amine adhesive on an $\mathrm{Al}$ alloy. Its advantages include high solubility both in water and epoxy resins, as well as the ability to form densely packed SAMs on an Al surface upon adsorption from 
both media. The adhesion promoter was studied as an adhesive monolayer adsorbed from an aqueous solution, or as an additive in an adhesive layer. An XPS study showed the formation of a monolayer on the passive Al monolayer, but a smaller degree of surface coverage was observed on intermetallic particles. FTIR studies confirmed the formation of strong promoter bonds to the surface of aluminum oxyhydroxide through acid-base interaction and its bidentateness. Corrosion tests showed strong inhibition and good adhesion for both promoter applications.

It should be noted that to improve the protective properties of polymer coatings, Al surface can be treated not only with solutions of AF but also alkanediphosphonates (ADPh). For example, de Souza et al. [62] studied the surface treatment of $1050 \mathrm{Al}$ alloy (mass. \% $0.339 \mathrm{Fe}, 0.177 \mathrm{Si}, 0.037 \mathrm{Mg}, 0.011 \mathrm{Mn}, 0.009 \mathrm{Cu}$ ) by a solution of ADPh of the Cardobond X4661 brand as a potential substitute for chromating. For comparison, tests of samples after treatment by immersion in an ADPh solution were carried out with samples of the same alloy chromatized by immersion in $\mathrm{Cr}(\mathrm{III})$ or $\mathrm{Cr}(\mathrm{VI})$ baths. It was found that surface treatment with ADPh was more effective if the samples were exposed in boiling water for the growth of oxide film before the inhibitor treatment. The test results showed excellent corrosion resistance of samples with oxide hydroxide $+\mathrm{ADPh}$ treatment compared to chromium treatment with either $\mathrm{Cr}(\mathrm{III})$ or $\mathrm{Cr}(\mathrm{VI})$. Chromatization in a solution with $\mathrm{Cr}(\mathrm{III})$ also provided better corrosion characteristics than in the case of $\mathrm{Cr}(\mathrm{VI})$.

Modification of the surface of an alumina sol-gel coating using aluminum tri-sbutoxide, $\mathrm{Al}(\mathrm{O}-s-\mathrm{Bu})_{3}$ proposed by Japanese researchers [63] deserves attention. As a result of the procedures described by the authors, the surface acquires a flower-like structure with 20 to $50 \mathrm{~nm}$ petals. According to their assumption, this structure is formed as a result of a reaction between water and the gel surface, which causes dissolution and reprecipitation of the alumina gel. In order to impart superhydrophobic properties to the alumina surface, the gel film was modified by a $1 \mathrm{mM} \mathrm{APhC} \mathrm{A}_{10} \mathrm{~F}_{17}$ solution in ethanol at room temperature. The contact angle of the $\mathrm{APhC}_{10} \mathrm{~F}_{17}$ modified smooth alumina gel film is more than $40^{\circ}$ higher than that of $\mathrm{APhC}_{10} \mathrm{~F}_{17}$ modified glass. This was explained by the fact that $\mathrm{APhC}_{10} \mathrm{~F}_{17}$ selectively adsorbs on metal oxide rather than on silica surface.

It may be assumed that further studies on superhydrophobization of the surfaces of $\mathrm{Al}$ and its alloys will allow one to find new ways to achieve this effect, including the use of fluorine-free APh that will reduce the ecological hazard of the surface modification process itself.

The prospects for the use of phosphonate COMs in medicine are no less inviting. According to [64], passivation of $\mathrm{Al}$ by $\mathrm{APh}$ is important for the development of biosensors for DNA recognition. Silanes in combination with Au usually serve as the primary anchor molecules on glass or quartz in these devices. The use of $\mathrm{Al}$ as a metallic component poses a problem, since the silane is attached both to it ( $\mathrm{Al}-\mathrm{O}-\mathrm{Si}$ ) and to glass $(\mathrm{Si}-\mathrm{O}-\mathrm{Si})$. Since it is desirable to prevent attachment of the molecular recognition functionality (silane) to the metal film, it is necessary to passivate Al before silanization of 
the biochip. Passivation of the Al layer plays an important role in reducing the background signal to low levels to ensure efficient operation of the biosensor.

Since APhs specifically react with hydrated Al oxide to form a strong bond through $\mathrm{Al}-\mathrm{O}-\mathrm{P}$, they were chosen as a passivating agent for use in biosensors. Indeed, the APh prevents subsequent chemical interaction of silane containing molecules with $\mathrm{Al}$ and capturing molecules can be attached to non-aluminum surfaces by a reaction with a specific functional group of the silane. However, it should be noted that the formation of SAMs by $\mathrm{APh}$ and attachment to Al requires careful preparation of its surface prior to monolayer self-assembly. In [63], the possibility to obtain SAMs by APh, which can be used to improve the selective silanization of sensors based on metal structures, was investigated. Another aspect of this study was to investigate the role of the length of the APh alkyl chain in the formation of effective passivating layers.

It was found that the values of the $\theta$ angle on the surface of oxidized $\mathrm{Al}$, treated with methanol solutions of $\mathrm{APhC}_{4}, \mathrm{APhC}_{10}$ and $\mathrm{APhC}_{18}$ increased with increasing alkyl length: $81^{\circ}, 103^{\circ}$ and $116^{\circ}$, respectively. The silanization was carried out at $115^{\circ} \mathrm{C}$ using GPS, $\mathrm{CH}_{2} \mathrm{OCHCH}_{2} \mathrm{O}\left(\mathrm{CH}_{2}\right)_{3} \mathrm{Si}\left(\mathrm{OCH}_{3}\right)_{3}$, i.e., 3-glycidoxypropyltrimethoxysilane. In the case of a silanized glass, $\theta=57^{\circ}$; similar treatment of $\mathrm{Al}$ yielded a close value of $\theta=59^{\circ}$.

The resistance of $\mathrm{APhC}_{18}$ and $\mathrm{APhC}_{10}$ films to silanization carried out by GPS was evaluated by an XPS study that did not detect silanes on the investigated surface (the Si2s and $\mathrm{Si} 2 \mathrm{p}$ spectra were recorded at the background level). This allowed the authors to come to the conclusion about the possibility of using hydrophobic APh to improve the operation of biosensors.

Magnesium and its alloys. Although $\mathrm{Mg}$ and its alloys, like $\mathrm{Al}$ alloys, are light and promising structural materials, it should be recognized that their passivation is not only much less investigated, but the use of inhibitors of their corrosion is also very limited.

This is largely due to the higher affinity of $\mathrm{Mg}$ for oxygen and sensitivity to impurities of less electronegative metals. The well known reaction of $\mathrm{Mg}$ with water accompanied by $\mathrm{H}_{2}$ evolution prevents the adsorption of many corrosion inhibitors. Not surprisingly, often only those chemical compounds are effective inhibitors for $\mathrm{Mg}$ and its alloys that are themselves limitedly soluble in water and capable of forming hardly soluble complex compounds or salts.

Apparently, the SAMs of alkyl- or perfluoroalkylphosphonic acids on the AZ 31 alloy (mass\%: $2.98 \mathrm{Al}, 0.88 \mathrm{Zn}, 0.38 \mathrm{Mn}, 0.0135 \mathrm{Si}, 0.001 \mathrm{Cu}, 0.002 \mathrm{Ni}, 0.0027 \mathrm{Fe}$, the rest $\mathrm{Mg}$ ) were obtained for the first time by immersing the samples in ethanol solution of the reagent for $1-72 \mathrm{~h} \mathrm{[65].} \mathrm{The} \mathrm{anticorrosive} \mathrm{and} \mathrm{chemical} \mathrm{properties} \mathrm{of} \mathrm{such} \mathrm{SAMs} \mathrm{were}$ characterized using static $\theta$ and dynamic $\theta_{\mathrm{a}}$ and $\theta_{\mathrm{r}}$ measurements, XPS, AFM and electrochemical measurements. It was found that the maximum $\theta_{\mathrm{a}}$ and $\theta_{\mathrm{r}}$ angles for SAMs in the case of $\mathrm{APhC}_{8}, \mathrm{APhC}_{10}, \mathrm{APhC}_{18}$ and $\mathrm{APhC}_{8} \mathrm{~F}_{10}$ were $105.1^{\circ} / 64.7^{\circ} ; 108.3^{\circ} / 69.6^{\circ}$, $111.9^{\circ} / 75.2^{\circ}$ and $115.2^{\circ} / 67.4^{\circ}$, respectively.

XPS studies showed that the film thicknesses of $\mathrm{APhC}_{8}, \mathrm{APhC}_{10}, \mathrm{APhC}_{18}$, and $\mathrm{APhC}_{8} \mathrm{~F}_{13}$ on the alloy were $0.8,1.2,1.7$, and $1.1 \mathrm{~nm}$, respectively. The $\mathrm{O} 1 \mathrm{~s}$ spectra 
confirmed that the SAMs formed by the APh are covalently bound to the surface of the oxide or hydroxide of the alloy in the form of a mono- or bidentate surface complex. The stability of the alloy surface with the SAM formed by the above acids was studied in aqueous solutions at $\mathrm{pH} 4.0,7.0$ and 10.0. The values of $\theta$ on the surface of SAM formed by $\mathrm{APhC}_{8}, \mathrm{APhC}_{10}$, and $\mathrm{APhC}_{8} \mathrm{~F}_{10}$ decreased rapidly during the first 5 min after immersion in all aqueous solutions and were less than $20^{\circ}$. However, $\theta$ for the SAM formed by $\mathrm{APhC}_{18}$ on alloy samples after immersion in aqueous solutions at $\mathrm{pH}$ 4.0. 7.0 and 10.0 for 5 min were $45.1^{\circ}, 89.3^{\circ}$ and $85.5^{\circ}$, respectively. Consequently, this SAM on the Mg alloy has better chemical stability among similar SAMs formed by the APh studied. The authors concluded that the molecular density of SAM on the Mg alloy will be higher than that of other APh films.

Later, Grubać et al. [66] studied the formation of SOMs on biodegradable AZ91D alloy (mass. \%: 8.6 Al, 0.19 Mn, 0.51 Zn, 0.05 Si, 0.025 Cu, 0.004Fe, Mg rest). APh was applied from a $0.7 \mathrm{mM}$ solution in ethanol, and to check the possibility of increasing the stability of the SAM, some of these samples were heated in an air convection oven at $120^{\circ} \mathrm{C}$ for $5.5 \mathrm{~h}$ and $24 \mathrm{~h}$.

The aim of the work was to slow down the degradation of implants in saline, after pre-forming a SAM from $\mathrm{APhC}_{12}$ and $\mathrm{APhC}_{18}$ on its surface coated by a natural oxide. The properties of the SAMs were studied by $\theta$ measurements, as well as by XPS, FTIR, EIS and polarization methods. According to FTIR and XPS studies, there are several different types of bond in phosphonic SAMs: $\mathrm{Mg}-\mathrm{O}-\mathrm{P}, \mathrm{P}-\mathrm{O}$ and $\mathrm{P}-\mathrm{O}-\mathrm{H}$. The high values of the contact angle of water indicate high homogeneity and ordering of the SAMs. The values of $\theta$ measured on the films of SAMs formed from $\mathrm{APhC}_{12}\left(106^{\circ}\right)$ and $\mathrm{APhC}_{18}\left(119^{\circ}\right)$ confirmed their high hydrophobicity, which is a consequence of several factors, including well-ordered and densely packed monolayers. Thermal treatment of alloy samples modified by SAMs formed from APh significantly reduced the corrosion current density and increased the polarizability of the electrode due to strengthening of the chemical bonds between the phosphonate and the $\mathrm{Mg}$ alloy. The protection efficiency of $\mathrm{APhC}_{12}$ and $\mathrm{APhC}_{18}$ films was $91 \%$ and $97 \%$, respectively.

In [67], SAMs were formed from carboxylic (SA, isostearic ISA) and phosphonic acids $\left(\mathrm{APhC}_{8}\right.$ and $\left.\mathrm{APhC}_{8} \mathrm{~F}_{13}\right)$ on a $\mathrm{Mg}$ alloy $(\mathrm{AZ31})$ by the vapor phase method at $150^{\circ} \mathrm{C}$ for 3-72 h. The anticorrosive and some chemical properties of the SAMs obtained were studied using $\theta$ measurements, XPS, AFM, EIS and polarization measurements. It was shown that the hysteresis of water contact angle with SAMs formed by carboxylic acids is much higher than for SAMs formed by $\mathrm{APhC}_{8}$ or $\mathrm{APhC}_{8} \mathrm{~F}_{13}$. Although SA and ISA have the same head group by which they are bound to the AZ31 surface, the packing density of the SAM can differ significantly.

The results of the XPS study showed that the packing density of $\mathrm{APhC}_{8}$ molecules is higher than that of $\mathrm{APhC}_{8} \mathrm{~F}_{13}$. The O1s peaks indicate a mixture of mono-, bi- or trivalent binding of these SAMs with the oxidized or hydroxylated alloy surface. Electrochemical 
measurements have shown that the SAM formed from APh have better corrosion resistance than the SAMs formed by the carboxylic acids.

The chemical stability of the alloy modified by a SAM was investigated by immersion of each sample in ultrapure water for a constant time with measurement of the $\theta$ angle. The changes in $\theta$ were compared with the duration of immersion of the sample in water. It was found that the $\theta$ angles on the surface modified by SA or ISA rapidly decreased in $10 \mathrm{~min}$ of immersion and amounted to less than $20^{\circ}$. The decrease in $\theta$ was explained by water adsorption and hydrolysis of the reagent bonds to the alloy surface. It was expected that the molecules of SA or ISA would be covalently attached to the surface of the Mg alloy, but the hysteresis of $\theta$ is relatively high in comparison with the SAM of these carboxylic acids adsorbed on other metals. The authors suggested that the reason for this is the presence of molecular defects in the SAM that arise due to the following two factors. The first of these is the presence of an impurity arising from the substrate, i.e., $\mathrm{Mg}$ alloy, and the second one is the low mobility of physically adsorbed molecules that cannot be assembled properly after they are adsorbed. Due to the presence of molecular defects, water can penetrate into the monolayer and reach the alloy surface. The density of $\mathrm{APhC}_{8}$ or $\mathrm{APC}_{8} \mathrm{~F}_{13}$ molecules on the $\mathrm{Mg}$ alloy was higher than in the SAMs formed by SA or ISA.

The authors [68] studied the formation and stability of SAMs formed by one of the most hydrophobic phosphonate reagents, $\mathrm{APhC}_{18}$, as a coating on a $\mathrm{Mg}$ alloy $(96 \% \mathrm{Mg}$, $3 \% \mathrm{Al}, 1 \% \mathrm{Zn}$ ) for biomedical applications. A carefully cleaned alloy sample was immersed for $48 \mathrm{~h}$ in a solution of dimethylsulfoxide (DMSO) containing $2 \mathrm{mM} \mathrm{APhC} \mathrm{C}_{18}$, then rinsed in DMSO and ultrasonicated for 3 minutes in deionized water to remove any excess surfactant. Its surface was immediately studied by FNIR, XPS and AFM. Similarly prepared other alloy samples were kept in a conventional laboratory atmosphere for 1 to 21 days, and then their surface was studied by the same methods. The FTIR study showed mono- and bidentate binding of $\mathrm{APhC}_{18}$ to the alloy surface, the results of XPS confirmed the formation of SAM, demonstrating the presence of P peaks persistently for 21 days and a decreasing intensity of Mg peaks. The AFM images also indicated the persistence of the $\mathrm{Mg}$ alloy coating over the entire test period. The authors reasonably concluded that the SAMs are stable under the chosen oxidation conditions.

Although the formation of SAMs by APhs on Mg or its alloys is still little studied, it can be said with certainty that they, like on Al and its alloys, are at least as good as, or even exceed in protective properties the more widely studied SAMs formed in solutions of carboxylic acids.

Titanium and its alloys. The high corrosion resistance of this light metal and its alloys in many corrosive environments at normal temperatures is well known, so it is not surprising that they are used as medical implants [69-76]. The utility of these materials can be greatly increased if the structure and chemistry of their surfaces can be controlled. For this purpose, an alloy, for example Ti45Nb, is first polished and anodized, providing a surface with a uniform oxide layer (a mixture of $\mathrm{TiO}_{2}$ and $\mathrm{Nb}_{2} \mathrm{O}_{5}$ ) [70]. After that a SAM formed by $\mathrm{APhC}_{16}$ is attached to the anodized surface. The SAM is characterized by its 
wetting properties and physical analysis of the surface. Using XPS analysis with angular resolution, information is obtained on the orientation, structure and thickness of the SAM, as well as on the chemistry of its interaction with the surface oxides on the alloy. Further FTIR studies of the surface gave information on the attachment of SAM to this alloy and opened the possibility of controlling its biocompatibility. Later, in [71], structural details of covalently fixed films on the oxidized surfaces of $\mathrm{Ti}, \mathrm{Nb}$, and $\mathrm{Ti} 45 \mathrm{Nb}$ alloys were compared. This became possible due to the configuration of the sample in which $\mathrm{APhC}_{16}$ was deposited on a thin film of the metal that was obtained by spraying it onto a doublesided polished silicon wafer and then oxidized. The samples were flat and reflective, so they were suitable for ellipsometry, $\theta$ measurements, XPS, AFM and FTIR. Precipitation from a $1.4 \mathrm{mM} \mathrm{APC}{ }_{16}$ solution in THF (at $120^{\circ} \mathrm{C}$ ) made it possible to obtain ordered films and to measure the differences between them and metal oxides $\left(\mathrm{TiO}_{2}, \mathrm{Nb}_{2} \mathrm{O}_{5}\right.$ and their mixtures on the alloy). The authors believe that the results of their studies made it possible to identify the mildest deposition procedures that ensure the production of uniform and durable ultrathin coatings.

Naturally, the stability of phosphonate SAMs is very important even on such a stable substrate as Ti alloys. It was noted in [69] that they may have a much higher resistance to the hydrolysis of adsorption bonds than silanes. In [72], the stability of SAMs formed by $\mathrm{APhC}_{18}$ on amorphous smooth Ti surfaces in $0.2 \mathrm{mM} \mathrm{APhC}_{18}$ in THF solution was studied. Already after $10 \mathrm{~s}$ of immersing the sample in this solution, the value of $\theta_{\mathrm{a}}$ reached $100^{\circ}$, and increased to $110 \pm 2^{\circ}$ after a few hours. These SAMs are resistant to common solvents, and the measured surface wettability after contact with them depends on the molecular volume of the solvents. Although low-molecular liquids penetrate into the SAM formed by $\mathrm{APhC}_{18}$, this was not observed for liquids with high molecular volume.

UV radiation $(\lambda=250 \mathrm{~nm})$, heat treatment and air plasma significantly improve the wettability of SAM $\left(\theta_{\mathrm{a}}\right.$ drops to $\left.0^{\circ}\right)$. The presence of phosphorus on the surface shows that the bond of the phosphonate head group with $\mathrm{TiO}_{2}$ through oxygen atoms is strong and can withstand even these conditions.

The shape-memory alloy nitinol (Ti-Ni) is a very promising material for implants. However, in contrast to $\mathrm{Ti}$, nitinol undergoes corrosion with the formation of $\mathrm{Ni}^{2+}$ on longterm contact with physiological solutions containing $\mathrm{Cl}^{-}$. In order to increase the stability of the nitinol surface, it was modified with $\mathrm{APhC}_{12}$ with terminal $\alpha-\mathrm{OH}$ and $\mathrm{CH}_{3}$ groups [74]. The SAMs obtained were characterized by $\theta$ measurements, EIS, X-ray and X-ray spectroscopy. Changes in the structure-sensitive impedance parameters correlated with changes in the interphase layer. Effective thermal annealing greatly improves the quality of films that behave like nonideal dielectrics, i.e., the resulting layers prevent the charge transfer reactions.

Later [75] it was shown that the foil surface of another alloy, Ti6Al4V, could be successfully modified by SAMs formed from $\mathrm{APhC}_{16}$ (about $4 \mathrm{~nm}$ thick). To this end, prepared foil samples were hanged vertically in $1 \mathrm{mM} \mathrm{APhC}{ }_{16}$ solution in THF. The solvent was then evaporated at $22^{\circ} \mathrm{C}$ until the liquid level fell below the foil. After that, the 
foil coated with $\mathrm{APhC}_{16}$ was annealed for $15 \mathrm{~h}$ in air at $140^{\circ} \mathrm{C}$. The physically adsorbed layers were removed from the surface by ultrasonic cleaning $(150 \mathrm{~W})$ in THF (twice) and with ethanol. Each ultrasonic cleaning lasted for 15 minutes. The modified foils were dried in nitrogen. Measurement of the control sample showed that the $\theta$ not exceed $60 \pm 2^{\circ}$, but $\theta=98 \pm 20^{\circ}$ for the modified surface, i.e., it becomes hydrophobic.

The authors assumed that the modifying layer consists of two $\mathrm{APhC}_{16}$ layers and confirmed this by means of XPS and FTIR. It was found that the first layer contains two types of $\mathrm{APhC}_{16}$ molecules which interpenetrate with each other. XPS measurements have proved the existence of covalent bonds $(\mathrm{P}-\mathrm{O}-\mathrm{Ti})$ on the modified surfaces. The hydrophobicity of the film indicates that the carbon chain of the molecules in the second molecular layer must be arranged on the outside. The authors associate the formation of the second molecular layer with reverse vesicles that can be formed in a THF solution and be adsorbed with rupture on the first molecular layer. In addition, the bond between the first and second molecular layer is strong, since it is able to withstand ultrasonic cleaning.

The mechanism of formation of $\mathrm{APhC}_{16}$ bilayers on the alloy was identified by observing the adsorption of $\mathrm{APhC}_{16}$ molecules. The high content of oxides/hydroxyls on Ti6Al4V surfaces significantly contributes to the formation of $\mathrm{APhC}_{16}$ bilayers. Annealing after self-assembly increases the stability of the $\mathrm{APhC}_{16}$ bilayers due to formation of pyrophosphates and $\mathrm{P}-\mathrm{O}-\mathrm{Ti}$ bonds that can withstand ultrasonic cleaning for at least $1 \mathrm{~h}$. The authors believe that modified Ti6Al4V can have good tribological properties and promote the adsorption of protein molecules on its surface.

In [76] films of $\mathrm{APh}$ with various chain lengths $\left(\mathrm{C}_{6}, \mathrm{C}_{10}, \mathrm{C}_{14}\right.$, and $\left.\mathrm{C}_{16}\right)$ were formed on $\mathrm{Ti}-6 \mathrm{Al}-4 \mathrm{~V}$ by chemisorption or electrochemical deposition. The alloy without and with modification was studied by various methods and it was found that long-chain acids form similar SAM, which results in more hydrophobic surfaces. It was found that the longer the alkyl, the greater the decrease in electron transfer across the interface that affects the corrosive behavior. The authors proposed an electrochemical method for creating SAM, which requires less time than the widely used method of immersing samples in solution.

It was found that its performance is close to that for the SAMs formed by short-chain $\mathrm{APh}$. The reason for this phenomenon stems from its mechanism and has basically three aspects. First, when a positive voltage is applied to the electrode surface, amphiphilic particles near the electrode are polarized, which allows them to stick to the surface in a better orientation. Thus, the cross-section of the molecule decreases as the surface is approached. Second, it is known from consideration of the mechanism of adsorption of these amphiphiles that the duration of the SAM formation is determined by the assembly of their molecules on the electrode surface, which has a high energy barrier. Application of a potential to the electrode makes it possible to overcome this energy barrier, and the assembly time is shortened. In other words, when the surface energy is greater, the activation energy for the organization of the adsorbate particles decreases. Finally, it is known that the role of the surface texture of the adsorbent makes a significant contribution to the organization of these molecules on it. Consequently, various oxides can contribute to 
changing the assembly time. In other words, different oxides can contribute to the change in the time constant, since the oxide obtained by anodizing contains less pollutants, which provides a better surface coverage and its structure is more uniform. SAMs precipitated chemically and electrochemically show similar characteristics if they are formed by shortchain APhs, so the methods for obtaining them can be considered to be equivalent. Taking into account that electrochemical deposition is faster, it allows better control of the interface between the organic monolayer and the substrate, and the SAM provides a higher corrosion resistance to the alloy. The authors concluded that the electrochemical method is an excellent way to assemble this type of SAM.

Copper and its alloys. Unlike carboxylic acids, APhs are little studied as reagents for the formation of SAM on $\mathrm{Cu}$, although it is one of the most important non-ferrous metals. Since the high adsorption and complexing ability of the phosphonate group has long been known $[3,4,24,25]$, it is not surprising that it was grafted not only to hydrocarbons or polymers, but also to representatives of heterocyclic corrosion inhibitors, e.g., triazoles, which are well known due to their effectiveness in protection of $\mathrm{Cu}$ and its alloys [77]. For example, Indian researchers [78] synthesized the phosphonates of 3-vanilidene-amino1,2,4-triazole (VATP) and 3-anisalidene-amino-1,2,4-triazole (AATP) that were studied as inhibitors of $\mathrm{Cu}$ corrosion in neutral aqueous solutions by polarization measurements and EIS. It was shown that their concentration in the lake water investigated, $C_{\text {in }}=4 \mathrm{ppm}$, was optimal for both inhibitors, but VATP was somewhat more effective than AATP. Since cooling water is a widespread type of such a medium, the use of corrosion inhibitors in it requires not only high efficiency in preventing corrosion of metals, but also compatibility with other functional reagents added to the water coolant, biocides in particular. Using cetyl-trimethylammonium bromide $(15 \mathrm{ppm})$ as an example, it has been proved that the phosphonates studied do not interfere with its antibacterial activity, and copper ions that pass into water are practically absent in the case of a mixture based on VATP. Based on the results of FTIR and energy dispersive X-ray (EDX) analysis, this was explained by the stability of the protective film that was formed due to insoluble complex compounds of organic molecules on the $\mathrm{Cu}$ surface.

Hungarian researchers studied monomolecular Langmuir-Blodgett (LB) layers formed on $\mathrm{Cu}(99.99 \%)$ and $\mathrm{Fe}(99.8 \%)$ by $\mathrm{APhC}_{18}$ or alkylhydroxamic acid $\left(\mathrm{AHC}_{18}\right)$ [79]. LB films were obtained using a trap, i.e., first, the acid was spread from a solution in chloroform onto an aqueous subphase $\left(\mathrm{pH} 5.6,23^{\circ} \mathrm{C}\right)$ and transferred to solid substrates at a speed of $10 \mathrm{~mm} / \mathrm{min}$. According to XPS results, the structures of LB films formed by $\mathrm{APhC}_{18}$ and $\mathrm{AHC}_{18}$ are very similar: the $d$ value of the layer of hydrocarbon tails is 1.9$2.1 \mathrm{~nm}$, while the $d$ of the head group layer is $0.3-0.35 \mathrm{~nm}$. The tilt angle of carbon chains with respect to the surface of the sample normal is estimated as $20-30^{\circ}$, and the organic molecules are bound to the substrate via their head groups. Analysis of the P2p and N1s lines indicates the presence of deprotonated head groups. The substrate line $\mathrm{Cu} 2 \mathrm{p}$ includes a component that can be attributed to $\mathrm{Cu}^{2+}$ ions in a thin $\mathrm{Cu}(\mathrm{OH})_{2}$ layer. The formation of 
LB films reduced the signal from the $\mathrm{OH}$ groups, which shows that the binding of the head groups to the surface is accompanied by removal of water molecules.

To analyze the composition and conformation of molecules in SAM, the authors also used sum-frequency vibrational spectroscopy (SFVS). Since the nonresonant background from the metal substrates complicated the analysis of the spectra, they prepared samples of the model system on glass. It was found that the alkyl chains of the adsorbed acids preferentially adopt the all-trans conformation and form an ordered structure. The upper limits for the mean tilt angle of the terminal methyl groups are $\sim 10-20^{\circ}$.

In [80] SAMs were formed on oxidized $\mathrm{Cu}$ by treatment with $\mathrm{APhC}_{10} \mathrm{~F}_{17}, \mathrm{APhC}_{8}$, $\mathrm{APhC}_{10}$, or $\mathrm{APhC}_{18}$, and then contact angles $\theta$ were measured and the surface was examined by XPS and AFM methods. It was found that the SAMs formed by $\mathrm{APhC}_{10} \mathrm{~F}_{17}$ or $\mathrm{APhC}_{18}$ are very hydrophobic $\left(\theta>140^{\circ}\right)$, while $\mathrm{APhC}_{8}$ and $\mathrm{APhC}_{10}$ form less hydrophobic SAMs: $\theta=76^{\circ}$ and $119^{\circ}$, respectively. The $\mathrm{Cu}$ surface modified by $\mathrm{APhC}_{18}$ is characterized by the lowest coefficient of friction that increases on transition to $\mathrm{Cu}$ coated with the SAMs: $\mathrm{APhC}_{10} \mathrm{~F}_{17}<\mathrm{APhC}_{10}<\mathrm{APhC}_{8}$. The highest friction coefficient was observed on oxidized $\mathrm{Cu}$. XPS has shown signs of a bidentate bond formed between $\mathrm{APh}$ and oxidized $\mathrm{Cu}$. The authors concluded that hydrophobic APhs can be useful as corrosion inhibitors in micro/nanoelectronic devices and/or to prevent wetting of the surface.

Chinese researchers proposed a two-stage process in order to provide a low friction coefficient and long durability to $\mathrm{Cu}$ surface [81]. First, a $\mathrm{Cu}$ plate was immersed for 2 hours in a hot $\left(75^{\circ} \mathrm{C}\right) 0.01 \mathrm{M} \mathrm{NaOH}$ solution to create a textured $\mathrm{Cu}_{2} \mathrm{O}$ film on it. It was then washed with deionized water and immersed in ethanol containing $10 \mathrm{mM} \mathrm{APhC} \mathrm{AP}_{18}$ or $\mathrm{APhC}_{12}$. After $24 \mathrm{~h}$ the plate was taken out, rinsed with water and ethanol, and dried in air.

The authors of [82] formed a thin film of $\mathrm{APhC}_{12}$ by molecular self-assembly on a copper oxide substrate. They studied its composition, structure, morphology and electrochemical behavior of a $\mathrm{Cu}$ electrode using XPS, IR spectroscopy, $\theta$ measurements and microscopy. XPS and IR spectroscopic results allowed the authors to conclude that $\mathrm{APhC}_{12}$ molecules can form tridentate bonds with the oxide surface during the SAM formation.

The results of electrochemical measurements confirmed the strong anticorrosive effect of the SAMs. The tribological properties of the $\mathrm{APhC}_{12}$ film adsorbed on a copper oxide substrate were examined in a linear reciprocating test in which sliding occurred against a $\mathrm{Si}_{3} \mathrm{~N}_{4}$ ball, then the surface of the $\mathrm{APhC}_{12}$ film was examined on a scanning electron microscope. All properties of the $\mathrm{APhC}_{12}$ film were compared and discussed from the point of view of ultrasound treatment carried out either before or after the modification of the oxidized $\mathrm{Cu}$ surface. An excellent tribological behavior was observed for the $\mathrm{APhC}_{12}$ film before sonication. In this case, a very low coefficient of friction $(\mu \sim 0.12)$ and an increase in the anti-wear resistance of the surface (100 times higher) were observed in comparison to the $\mathrm{APhC}_{12}$ film after ultrasonic treatment or to oxidized $\mathrm{Cu}$ without a SAM. This indicates that physically adsorbed $\mathrm{APhC}_{12}$ molecules removed by ultrasonic surface treatment are important for maintaining the required wear resistance. 
The authors of [83] successfully used $\mathrm{APhC}_{18}$ to obtain a superhydrophobic surface on an oxidized $\mathrm{Cu}$ mesh intended for self-cleaning and oil/water separation. The $\mathrm{Cu}$ mesh was first oxidized by immersing it for 30 minutes in an aqueous solution of $1.0 \mathrm{M} \mathrm{NaOH}$ and $0.05 \mathrm{M} \mathrm{K}_{2} \mathrm{~S}_{2} \mathrm{O}_{8}$ at room temperature; as a result, its surface was covered with microand nanoscale $\mathrm{Cu}(\mathrm{OH})_{2}$ particles. The mesh was then immersed in a $0.2 \mathrm{mM} \mathrm{APhC}_{18}$ solution in THF, where a SAM was formed so rapidly that after $1 \mathrm{~s}, \theta \sim 158.9^{\circ}$ was provided for wetting with water and $0^{\circ}$ with oil. In addition, the mesh acquired a selfcleaning property and the ability to be reused for effective separation of a mixtures such as gasoline/water and diesel oil/water. It is interesting that direct oxidation of $\mathrm{Cu}$ creates a "water-repellent" oil/water-separating mesh with underwater superoleophobicity. If, however, the oxidized mesh is covered with a SAM formed by $\mathrm{APhC}_{18}$, then it has superhydrophobicity and superoleophilisity and separates insoluble hydrocarbons from water with removal of the former.

It is known that numerous $\mathrm{Cu}$ alloys are widely used in practice and have good decorative properties. This, however, does not mean that they can always be used without corrosion protection means. A lot of azoles, thiazoles or salts of carboxylic acids have long been widely used as corrosion inhibitors for $\mathrm{Cu}$ alloys. Although APhs have not been sufficiently investigated, it follows from the examples discussed above that the prospects of their application for the protection of $\mathrm{Cu}$ alloys are quite real. For example, the authors of [84] obtained stable, well-ordered SAMs formed on an oxide film of the CuNi alloy $(55 \% \mathrm{Cu} / 45 \% \mathrm{Ni})$ by precipitation from the $\mathrm{APhC}_{18}$ solution and 16-phosphonohexadecanoic acid $\left(\mathrm{APhC}_{16} \mathrm{COOH}\right)$. The surface of the alloy modified by the adsorption of $\mathrm{APhC}_{18}$ exhibits enhanced corrosion resistance, and the $\mathrm{APhC}_{16} \mathrm{COOH}$ film can be used for further surface reactions leading to the formation of a polymer coating on a well-ordered film.

Zinc and its alloys. The known problem of replacing metal passivation with solutions of carcinogenic $\mathrm{Cr}(\mathrm{VI})$ compounds is acute in the case of $\mathrm{Zn}$, its alloys and coatings. The corrosion inhibition in neutral aqueous solutions is often explained by chelation between zinc and an organic compound or ion and formation of a protective layer with a complex composition on the metal surface $[4,14,85]$. The possibility of such a reaction of $\mathrm{Zn}$ with $\mathrm{APhs}$ has long been known, therefore it is not surprising that APhs attracted the attention of researchers. Apparently, one of the first studies on the formation and determination of the composition of ultrathin $\mathrm{APh}$ films on polycrystalline $\mathrm{Zn}$ was carried out in [86]. Its authors studied the effect of SAM formed by $\mathrm{APhC}_{5}$ and $\mathrm{APhC}_{14}$ from solutions in absolute ethanol or its mixture with $\mathrm{H}_{2} \mathrm{O}(75: 25 \%)$ on the wetting properties and properties of surface layers. Although a mixed solvent led to predominantly oxidized $\mathrm{Zn}$ substrates, the best monolayer coatings with both APhs were obtained for $\mathrm{Zn}$ in ethanol in $15 \mathrm{~min}$ of UV surface treatment. XPS results showed that this treatment minimized the amount of adsorbed impurities on the surface, and the stoichiometry of the grafted films was closer to the theoretical value. Measurements of the $\theta$ angle and Kelvin probe measurements (with $\mathrm{Cr} / \mathrm{Ni}$ wire as a vibrating reference electrode) confirmed that the best films were obtained 
for $\mathrm{APhC}_{14}$ due to its longer alkyl. However, the cyclovoltammetric and polarization curves obtained in $0.5 \mathrm{M} \mathrm{NaCl}$ and $0.1 \mathrm{M} \mathrm{NaOH}$ solutions do not indicate the ability of the these films on $\mathrm{Zn}$ to withstand the action of these corrosive media. Unfortunately, the authors did not conduct direct corrosion tests or electrochemical experiments under milder conditions. This makes it impossible to estimate the passivating properties of SAMs on Zn.

Kalman et al. [87-89] studied in detail the possibility of $\mathrm{Zn}$ passivation with solutions of $\alpha, \omega$-diphosphonic acid $\left(\mathrm{PhC}_{n} \mathrm{Ph}\right)$. First they studied the effect of aqueous solutions of $\mathrm{PhC}_{n} \mathrm{Ph}$ with different lengths of the hydrocarbon part $(n=5 ; 7 ; 8 ; 12)$ [87]. It was found that in $24 \mathrm{~h}$ of treatment in $\mathrm{PhC}_{n} \mathrm{Ph}$ solutions $(n=8$ and 12), $\mathrm{Zn}$ corroded, and in the case of $\mathrm{PhC}_{7} \mathrm{Ph}$, its thick film was deposited. No visible changes of the surface were observed on $\mathrm{Zn}$ treatment in $\mathrm{PhC}_{5} \mathrm{Ph}$ solution, therefore, the properties of the film formed by it were studied in detail. The coating, stability and anticorrosive protection of these films were monitored by EIS, and the effect of $\mathrm{PhC}_{5} \mathrm{Ph}$ on the electrochemical behavior of $\mathrm{Zn}$ was estimated from polarization curves. Wetting of the surface was determined by measuring $\theta$. It has been shown that the creation of thin mono- or multi-layer films formed by selfassembly of $\mathrm{PhC}_{7} \mathrm{Ph}$ molecules on $\mathrm{Zn}$ surface can be an alternative to chromate passivation. They can prevent the dissolution of $\mathrm{Zn}$ due to their dense and stable structure.

In [88], the reaction of aqueous solutions of $\mathrm{PhC}_{5} \mathrm{Ph}$ and $\mathrm{PhC}_{7} \mathrm{Ph}$ with the surface of high purity polycrystalline $\mathrm{Zn}$ at room temperature was investigated. The X-ray powder diffraction (XRD) and XPS measurement results indicate the formation of a hydrophilic zinc phosphonate crystalline film on the metal surface. Model zinc-diphosphonate compounds simulating those found on the $\mathrm{Zn}$ surface were synthesized. Their composition was close to the phosphonate group: $\mathrm{Zn}^{2+}$ ratio of $1: 1$. Reactions with both $\mathrm{PhC}_{n} \mathrm{Ph}$ resulted in a significant protective effect of $\mathrm{Zn}$ from corrosion, although the structure and quality of the layers formed were different.

In order to better understand the inhibition mechanism, identical measurements of the corrosion characteristics of $\mathrm{Zn}$ in a $\mathrm{Na}_{2} \mathrm{SO}_{4}$ solution and the structure of layers formed in aqueous and ethanol solutions of $\mathrm{PhC}_{5} \mathrm{Ph}$ on mechanically polished $\mathrm{Zn}$ samples were performed in [89]. Although the protective layers formed in ethanol and in aqueous solution have significant differences, their protection efficiency is approximately equal in short-term ( 4 and $24 \mathrm{~h}$ ) tests in which the protective properties were evaluated by EIS.

Perkins [90] considered the two most promising schemes for attaching organic molecules to metal oxides, using thiols and phosphonic acids. He compared the efficiencies of these two anchor groups on zinc oxide by analyzing the chemical and physical properties of $n$-hexane derivatives. The surface of thin polycrystalline $\mathrm{ZnO}$ films and $\mathrm{ZnO}(0001)-\mathrm{O}$ crystals modified with 1-hexanethiol (HT) and $\mathrm{APhC}_{6}$ was investigated using the quartz microbalance (QCM) method in a flow reactor, angular and $t$-dependent XPS, and by measurements of the $\theta$ angle. The results of QCM weighting showed that the alkyl chain anchored by $\mathrm{APhC}_{6}$ provides significant protection against $\mathrm{ZnO}$ corrosion, reducing the etching rate of with respect to uncoated $\mathrm{ZnO}$ surface more than 9-fold. On the contrary, monolayers formed from HT molecules possessed greater ionic permeability and 
smaller hydrophobicity, i.e., they were more defective. Using XPS, the $d$ of the SAMs formed by the two hexane derivatives was determined. It was found that in the case of $\mathrm{APhC}_{6}, d$ is approximately twice as large as $d$ of the SAM formed by HT. It was found that previous statements about the high thermal stability of alkanethiol SAMs on $\mathrm{ZnO}$ are suspicious. The author concluded that the phosphonate group is preferable to the HS group for the attachment of short alkyls to $\mathrm{ZnO}$.

In [91], $\mathrm{ZnO}$ films sputter-deposited on $\mathrm{Au}$ or silicon substrates were modified by treatment with $\mathrm{APhC}_{8}, \mathrm{APhC}_{18}$ or $\mathrm{APhC}_{8} \mathrm{~F}_{13}$ in order to study their binding to the $\mathrm{ZnO}$ surface and the degree of packing of the alkyl chain. The characteristics of APh-modified $\mathrm{ZnO}$ surfaces were obtained by the XPS method, infrared absorption reflection spectroscopy (IR-RAS), AFM and $\theta$ measurements. XPS studies showed that oxygen plasma treatment for 2 min creates reactive oxygen species on the $\mathrm{ZnO}$ surface, which provides a more reliable binding of $\mathrm{APh}$ to the $\mathrm{ZnO}$ surface. IR-RAS analysis proved that $\mathrm{APhC}_{18}$ binds to the $\mathrm{ZnO}$ surface in a predominantly tridentate way to form dense, well-packed SAMs. AFM images and $\theta$ measurements also indicate a good surface coating by the $\mathrm{APh}$ with virtually no multilayer coating. Although no corrosion or electrochemical experiments were performed, the results suggest that the anticorrosion resistance of $\mathrm{ZnO}$ should increase.

Phosphonic acids were studied for modifying the interface in organic solar cells to improve the work function between the organic active layer and various metal oxides, such as the In-Zn alloy oxide used as electrodes [92]. In this respect, it is interesting the report about the fast method for deposition of APh molecules on the surface of metal oxides, including $\mathrm{ZnO}$ [93].

In this method, a solution of pentafluorobenzylphosphonic acid $\mathrm{C}_{6} \mathrm{~F}_{5} \mathrm{CH}_{2} \mathrm{P}(\mathrm{O})(\mathrm{OH})_{2}$ (PFBPA) was deposited on various oxides, including $\mathrm{ZnO}$, on substrates for spray coating heated to $t=25-150^{\circ} \mathrm{C}$ with an exposure time of $60 \mathrm{~s}$. This method for the preparation of an ultrathin coating and the change it brings to the work function of the oxide were compared with the more traditional method of immersing the sample in a solution for $1 \mathrm{~h}$. It was found that the shift of the work functions and the surface coating by PFBPA were similar or greater than in the traditional method. When the deposition temperature was increased, the surface coverage and the shift of the work function were improved. It is significant that the rapid action of spray coating results in smaller etching of zinccontaining oxides than the immersion method. These results show the possibility of a new method for modifying the surface of metal oxides by phosphonic acid, which exceeds other methods that require a prolonged action of modifying reagents.

The authors of [94] studied the SAMs formed on $\mathrm{ZnO}$ by phenylphosphonic acid $\mathrm{C}_{6} \mathrm{H}_{5} \mathrm{HP}(\mathrm{O})(\mathrm{OH})_{2}(\mathrm{PhPhA})$ as an alternative to transparent electrodes in optoelectronic devices. They used thermal desorption spectroscopy (TDS), XPS and near-edge X-ray adsorption fine structure (NEXAPS) and quantum-chemical DFT calculations to evaluate the thermal stability and orientational ordering of the SAMs on the $\mathrm{ZnO}$ surface. It was shown that the adsorbed $\mathrm{PhPhA}$ molecules on all surfaces remain stable up to $550 \mathrm{~K}$. However, at higher temperatures, the $\mathrm{C}-\mathrm{P}$ bond is cleaved and dissociative desorption 
occurs, which gives two distinct peaks. Based on DFT calculations, they were attributed to protonated and deprotonated chemisorbed $\mathrm{PhPhA}$ molecules, which can be linked with $\mathrm{ZnO}$ by tri- and bidentate bonds.

As noted above, during the last decade there has been a great interest in the electronic and photonic properties of $\mathrm{ZnO}$ nanostructures, and it was assumed that they can be applied in solar cells and laser diodes. Indeed, SAMs were used to improve the charge transfer between organic layers and metal oxides by covalently bonding an ultrathin film to the $\mathrm{ZnO}$ surface [95]. This can have several effects, including the passivation of surface charge traps to improve direct charge transfer, adjustment of the energy level shift between semiconductors and organic layers, and an effect on the morphology of the upper organic layer. Control of the surface functionalization by chemical attachment of organic acids to it is of great importance.

In [96], $\mathrm{ZnO}$ nanoparticles were modified by forming SAMs on their surface with $\mathrm{APhC}_{18}, \mathrm{PhC}_{12} \mathrm{Ph}$ or 16-phosphonohexadecanoic acid $\left(\mathrm{PhC}_{16} \mathrm{COOH}\right)$. Such SAMs are particularly useful when they contain modifying tail groups as they create bifunctional thin films that provide an efficient and inexpensive method for adapting the surface properties of nanoparticles. The authors carried out a complex study of anisotropic films of these acids chemically bonded to the surface of $\mathrm{ZnO}$ nanoparticles. It was found that the work function required for integration of electronic devices strongly depends on the type of the phosphonic acid. The thin film on the particle proved to be durable, as it remained unchanged after storage in the environment ( 1 year) and even when exposed to rinsing with a solvent and in an acid-base bath. This makes it possible to impart various physical and chemical properties to $\mathrm{ZnO}$ nanoparticles depending on the nature of the tail group in phosphonates. For example, by choosing it, the hydrophobicity of the surface can be increased when it ends with an alkyl, and vice versa, decreased if the tail group is an acid. In addition, the hydrogen bond between the acid terminal groups in the SAM can improve the film stabilization.

In studies of modified nanoparticles, NMR and SEM methods were very useful. It was shown that the $\mathrm{COOH}$ group does not participate in binding to the surface, which slightly increased the average particle size. If $\mathrm{PhC}_{12} \mathrm{Ph}$ is used, it is possible to form multilayer films with precisely controlled thickness and sequence of layers, which expands the scope of possible applications of such particles. Thus, the work functions of the nanoparticles can be tuned by adjusting the coating surface, the $d$ of the film, and the type of modifying acids.

The successful use of mono- and diphosphonic acids for modifying the surface of $\mathrm{Zn}$, $\mathrm{ZnO}$ and its nanoparticles, which can improve their corrosion resistance and other valuable properties, suggests that they can be used with the same purpose for zinc alloys. It was confirmed by the example of the treatment of the $\mathrm{Zn}-(0.5,5.0$, or $55 \% \mathrm{Al})$ [97] and $\mathrm{Zn}-$ $1 \% \mathrm{Mg}-1 \% \mathrm{Al}$ alloys [98] with $1 \mathrm{mM} \mathrm{APhC}_{18}$ solution in ethanol. In the former case, it was found that, judging by the values of the $\theta$ angle measured by the static method, hydrophobicity of the alloy surface is achieved even on the alloy containing $0.5 \% \mathrm{Al}$, but it already disappears in the second cycle of 10-minute exposure of a sample in bidistilled 
water. The authors believe that the resulting film containing Al hydroxide is not sufficiently stable to prevent dissolution and precipitation of the phosphonate salt film, while a SAM is not formed. Apparently, the alloy dissolves in the ethanol solution and the $\mathrm{Zn}^{2+}$ that appears in it is coordinated with $\mathrm{APhC}_{18}$. This process stops when the zinc phosphonate deposited on the alloy surface forms a dense layer and $\mathrm{Zn}^{2+}$ ceases to pass into the solution. On alloys with a higher $\mathrm{Al}$ content $(\geq 5 \%)$, the SAM formed by $\mathrm{APhC}_{18}$ makes the surface not only more hydrophobic (up to $98^{\circ}-110^{\circ}$ ) but also more stable (at least 9 cycles mentioned above). The authors conclude that APhs can be used for temporary corrosion protection and also as promoters of adhesion on coatings of $\mathrm{ZnAl}$ alloy containing $>5 \% \mathrm{Al}$.

Another work of German researchers [98] is a logical continuation of the study on $\mathrm{Zn}-\mathrm{Al}$ alloys discussed above and of the conclusions made in it. They investigated the adsorption of $\mathrm{APhC}_{18}$ and the stability of the SAMs formed by it on the alloy surface, not only with a low $\mathrm{Al}$ content, but also with addition of $\mathrm{Mg}$, i.e., metals whose oxidized surfaces are more hydroxylated than on $\mathrm{Zn}$. In addition, the authors used a relatively new fast $(60 \mathrm{~s})$ plasma processing method, the so-called SHC, to obtain a thin layer of a mixed oxide in which the content of the doping components was significantly higher than that of $\mathrm{Zn}$ itself. The formation and stability of $\mathrm{APhC}_{18}$ monolayers were studied on the surfaces of this alloy, previously subjected to modification with various plasma treatments or without it. Self-organization of monolayers was confirmed by means of XPS and IRRAS, and their stability by $\theta$ measurements as well as by the cyclic voltammetry method to estimate the effect of SAMs on the current density of the redox reaction.

It was found that the composition of the oxide layer strongly affected the formation of $\mathrm{SAMs}$ by $\mathrm{APhC}_{18}$. Better ordering and higher stability in aqueous solutions were observed for surfaces enriched by $\mathrm{Mg}$ and $\mathrm{Al}$ oxides as compared to $\mathrm{ZnO}$. A combination of an oxide enriched by $\mathrm{Al}$ and $\mathrm{Mg}$ with a SAM formed by $\mathrm{APhC}_{18}$ leads to strong inhibition of oxidation-reduction reactions of the surface of the oxide film. The strongest inhibition was observed after treatment of the alloy surface with $\mathrm{Ar} / \mathrm{H}_{2}+\mathrm{O}_{2}$ plasma, followed by the formation of SAMs from an $\mathrm{APhC}_{18}$ solution.

Other metals and alloys. Of course, the above sections of this review do not cover studies of the passivating properties of mono- and diphosphonic acids (or their salts) with respect to all metals and alloys. Apparently, attention to this issue has grown so much over the last decade that its more comprehensive coverage and analysis go beyond the scope of one review article. Here we limit ourselves to a few examples of studies whose results are useful for the possible application of the passivating properties of phosphonates not only for the object in question but also for a broader range of metals and alloys.

For example, Ni that is widely used as an important alloying component of steels and alloys, including those in many biomaterials and in electronics, has relatively high corrosion resistance. However, its cations are toxic, so it is necessary to prevent their release into the human body. The properties of electronic devices deteriorate or they fail, even at a low corrosion rate of the structural material. In this connection, APhs, which, as already noted, 
are more strongly chemisorbed on oxides or oxidized surfaces of many metals than carboxylates, were also investigated on Ni foils with natural oxide coating [99].

The authors of this work used two methods (immersion in organic solvents in THF and aerosol spraying) to form a monolayer with $\mathrm{APhC}_{8}, \mathrm{APhC}_{11}$ or $\mathrm{APhCl}_{8}$ on the oxide surface. Although both methods made it possible to form SAMs, the aerosol method requires less time for its complete formation, lower temperature, and solution concentration than the immersion method. The SAMs obtained were studied by FTIR, AFM, SEI, cyclic voltammetry, measurements of the $\theta$ angle, and mass spectrometry with laser desorption ionization. The total of these results allowed the authors to conclude that the SAMs formed upon adsorption of $\mathrm{APhs}, \mathrm{APhC}_{18}$ in particular, on the surface of Ni oxide can reduce the surface electrochemical activity, often at the first stage of corrosion. The formation of such SAMs on the surface of Ni covered by native oxide is an excellent surface modification that can be used as a "building block for future applications in corrosion barriers, biomaterials and electronics".

Although it has not been possible to find reports on the formation of SAMs upon adsorption of APhs on Co itself, studies of this kind are widely known for $\mathrm{Co}-\mathrm{Cr}$ alloys [100-103]. These alloys are widely used in cardiovascular stents, orthopedics and dentistry. For example, according to [102], out of 10 commercially available stents, 8 are made of 316L stainless steel, and 1 is made of L605 (mass\% $51 \mathrm{Co}, 20 \mathrm{Cr}, 15 \mathrm{~W}, 10 \mathrm{Ni}$ and $\mathrm{Fe}<3$ ). However, such drug-eluting stents can cause inflammatory and other adverse reactions due to their polymeric coating. Since modification of the surface allows it to be adapted to various applications in medicine, a SAM was formed on the $\mathrm{Co}-\mathrm{Cr}$ alloy oxide layer using the $\mathrm{APhC}_{18}$ deposition method. Samples of the alloy modified in this way were tested for resistance to oxidizing conditions in a laboratory medium and in phosphate buffer solution (PBS) with a $\mathrm{pH}$ of 7.4 for 1 to 14 days, and then studied by XPS, AFM and $\theta$ measurements. The stability of the SAM and the hydrophobicity of the alloy surface throughout the study were confirmed [101,103].

Kaufman et al. [102] noted the disadvantages of mechanical polishing compared to electrochemical polishing that can provide a cleaner surface of the substrate. They studied the formation of SAMs and their stability upon adsorption of $\mathrm{APhC}_{12}$ and $\mathrm{APhC}_{10} \mathrm{COOH}$ on the electrochemically polished surface of L605 alloy. A combination of two methods was used: precipitation of SAM from $1 \mathrm{mM}$ solution of APh in THF $(24 \mathrm{~h})$ and fivefold immersion of samples in the same solution for $1 \mathrm{~min}$ each time, with slow evaporation of the solvent between the immersions. The surface of the alloy samples with SAMs was studied by FTIR, XPS, AFM and $\theta$ measurements. The results of the studies showed that the SAMs obtained were homogeneous and well-ordered. Long-term stability of the SAMs was studied in tris-buffered saline (TBS) that imitates physiological medium. The tests were performed for 28 days at $37^{\circ} \mathrm{C}$. It was found that desorption of both APhs from a SAM occurs in two stages. First, within 1-3 days, rapid significant desorption of an APh takes place, followed by slower desorption for 28 days until the SAM action ceases. It was concluded that it is 
necessary to continue to perfect methods "that can improve the long-term stability of SAMs on electropolished $\mathrm{Co}-\mathrm{Cr}$ alloy for stent and other biomedical applications".

Taking into account the results of SAM studies on various metals, the author of this review believes that it is promising to use reagents more hydrophobic than $\mathrm{APhC}_{12}$, primarily $\mathrm{APhC}_{18}$, and to search for effective formulations of $\mathrm{APhs}$ with other organic compounds. In addition, it seems important to pay more attention to the preparation of a certain surface morphology and to the formation of SAMs from vapor phase at elevated temperatures.

We have already mentioned above the modification of the surface of an In- $\mathrm{Zn}$ alloy by $\mathrm{APh}$ [93]. In [104] it was carried out on another alloy (In-Sn) by two different methods, using $\mathrm{APhC}_{10}, \mathrm{APhC}_{16}$ or $\mathrm{APhC}_{18}$. The stability of the $\mathrm{SAMs}$ measured by their ability to block charge transfer was investigated using cyclic voltammetry and EIS. SAMs were tested for long-term stability in the PBS and in ultrasonic washing. As was to be expected, the $\mathrm{SAM}$ formed by $\mathrm{APhC}_{18}$ was much more resistant to ultrasonic washing and was more effective in blocking the charge transfer than the $\mathrm{SAM}$ formed from $\mathrm{APhC}_{12}$ or $\mathrm{APhC}_{16}$, the monolayer of which was significantly damaged. Similar observations were also made by XPS in the case of $\mathrm{APhC}_{18}$, regardless of the method of SAM formation. However, after 7 days of immersion of the alloy samples with such a SAM in PBS, the best blocking of the charge transfer in the $\mathrm{Fe}(\mathrm{CN})_{6}^{3-} / \mathrm{Fe}(\mathrm{CN})_{6}^{4-}$ reaction was shown by the SAM formed by simple immersion in THF solution for 2 hours rather than by the Langmuir-Blodgett method.

As for other metals, alloys or their oxides, their modification by phosphonates is often less successful and/or already considered in earlier review [10].

\section{Conclusions}

1. Water-soluble mono- and diphosphonic acids, due to the high reactivity of their functional groups and the presence of hydrophobic alkyls or other hydrocarbon substituents in them, can facilitate the passivation of metals in aqueous media with nearneutral $\mathrm{pH}(6-9)$. Monoalkylphosphonates $\left(\mathrm{APhC}_{n}\right)$ are studied most thoroughly, and compounds with $\mathrm{C}_{8}-\mathrm{C}_{12}$ have the highest passivating ability in these media among them. They act due to strong adsorption on oxidized surfaces of iron and steels or by the "nonoxide" passivation mechanism. APhs, having effective passivating properties, are less hydrophobic than alkylcarboxylates, alkyl or dialkyl phosphates with the same alkyls. In addition, even lower phosphonates, for example $\mathrm{APhC}_{3}$, which have poor protective properties in neutral solutions, can facilitate the passivation of steel in combination with $\mathrm{Zn}^{2+}$ cations. Monoalkylphosphonates $\left(\mathrm{APhC}_{\mathrm{n}}\right)$ were studied most thoroughly. Of these, the best passivating ability in these media is shown by compounds with $\mathrm{C}_{8}-\mathrm{C}_{12}$. They can act both due to strong adsorption on oxidized surfaces of iron or low-carbon steel, and by the "non-oxide" passivation mechanism, i.e., protect in the absence of any surface oxide film. 
2. Due to low solubility, $\mathrm{APhC}_{n}$ with $n \geq 12$ are difficult to use in the form of aqueous solutions, but they are capable of forming passivating self-assembled monolayers (SAMs) on the surface of many metals, including oxidized ones. These SAMs are often applied from organic solvents (alcohols, THF, dimethylformamide, etc.). Self-assembly of these molecules and the interaction of their head (anchor) phosphonic groups with the surface takes some time. Such SAMs are also useful when they contain modifying tail groups. While $\mathrm{SAMs}$ with a tail $\mathrm{CH}_{3}$ group imparts high hydrophobicity, the SAMs formed by $\mathrm{APhC}_{n} \mathrm{Y}$ (where $\mathrm{Y}=\mathrm{COOH}, \mathrm{P}(\mathrm{O})(\mathrm{OH})_{2}$ or a similar tail group) creates a more hydrophilic surface. $\mathrm{APhC}_{n} \mathrm{Y}$ compounds can form bifunctional thin films that provide an efficient and inexpensive method for adapting the surface properties of nanoparticles or improve the adhesion of the second layer or a paint coating.

3. $\mathrm{APhC}_{18}$ is one of the most versatile and efficient passivators. It forms a well-ordered SAM on oxidized metals ( $\mathrm{Fe}, \mathrm{Al}, \mathrm{Mg}, \mathrm{Ti}, \mathrm{Cu}, \mathrm{Zn}, \mathrm{Ni}, \mathrm{Co}, \mathrm{In}$ ) or their alloys. It is not removed by washing with a pure solvent, even under ultrasonic treatment. Its molecules are usually covalently bound to the substrate; the phosphonate ligand is bidentate. The preliminary preparation of the metal surface and its heat treatment after the application of a SAM $\left(0.5-1.0 \mathrm{~h}, 100-120^{\circ} \mathrm{C}\right)$ play an important role in improving the stability of the $\mathrm{SAMs}$ formed by $\mathrm{APhC}_{18}$. The stability of the SAMs formed is in many cases higher than that of the SAMs formed from higher carboxylic acids or alkylsilanes. It is interesting to use $\mathrm{APhC}_{18}$ and its homologues to form SAMs that can create superhydrophobic surfaces on metals. Although a realization of this possibility on Al using $\mathrm{APhC}_{14}$ was reported, but, unlike with higher carboxylic acids, it was practically not studied in relation not only to Al alloys but also to other metals.

4. In the bisphosphonate series, [(3,5-di(perfluoroctyl)phenylhydroxymethylene]bisphosphonic acid deserves attention. The passivation of metals (steel, Ti) with this acid can be performed from an aqueous solution. In this case their surfaces become somewhat more hydrophobic than in the case of $\mathrm{APhC}_{18}$ treatment and lipophobic, and retain these properties even on prolonged immersion in water at elevated temperatures.

5. In order to quicken the formation of a SAM and increase its stability, the following methods were suggested apart from simple immersion of samples with a thoroughly cleaned surface in a passivating solution for several hours:

- immersion in this solution with electrode potential different from $E_{\text {cor }}$ is applied to the sample (electrochemical deposition of SAM);

- periodic immersions of the sample in the solution for a short time with intermediate slow drying;

- spraying of this solution on the surface being protected;

- SAM application from an APh in vapor phase at elevated temperature.

Although there is some progress in the formation of SAMs by APhs using these methods, the need for further work in this field is obvious. 


\section{References}

1. N.M. Dyatlova, V.Ya. Temkina and K.I. Popov, Kompleksony $i$ Kompleksonaty Metallov (Metal Complexones and Complexonates), 1988, Moscow, Khimiya. 544 pp. (in Russian).

2. Reviews on Corrosion Inhibitor Science and Technology, Eds. A. Raman and P. Labine, NACE International, Houston, 1993.

3. Corrosion Inhibitors, Ed. A.D. Mercer, The Institute of Materials, London, 1994. $163 \mathrm{pp}$.

4. Yu.I. Kuznetsov, Organic Inhibitors of Corrosion of Metals, New York, Plenum Press, 1996, 283 pp.

5. Reviews on Corrosion Inhibitor Science and Technology, Vol. 2, Eds. A. Raman and P. Labine, NACE International, Houston, 1996.

6. The Science and Technology of Industrial Water Treatment, CRC Press, Boca Raton, FL, 2010.

7. Mineral Scales and Deposits: Scientific and Technological Perspectives, Eds. Z. Amjad and K. Demadis, Elsevier, Waltham, MA, USA, 2015.

8. W. Gao and L. Reven, "Solid-State NMR Studies of Self-Assembled Monolayers," Langmuir, 1995, 11, 1860-1863.

9. Ch. Bram, Ch. Lung and M. Stratman, "Self assembled molecular monolayers on oxidized inhomogeneous aluminum surfaces," Fresenius J. Anal Chem., 1997, 358, $108-111$.

10. J.G. Van Alsten, "Self-Assembled Monolayers on Engineering Metals: Structure, Derivatization, and Utility," Langmuir, 1999, 15, 7605-7614.

11. P.G. Mingalyov and G.V. Lisichkin, "Chemical Modification of Oxide Surfaces with Organophosphorus(V) Acids and Their Esters," Russ. Chem. Rev., 2006, 75, no. $6,541-557$.

12. I. Felhősi, J. Telegdi, G. Pálinkas and E. Kálmán, "Kinetics of self-assembled layer formation on iron," Electrochim. Acta, 2002, 47, no. 13-14, 2335-2340.

13. I. Felhősi and E. Kálmán, "Corrosion protection of $\alpha, \omega$-diphosphonic acid layers," Corros. Sci., 2005, 47, 695-708.

14. Yu.I. Kuznetsov, "Organic corrosion inhibitors: Where are we now? A review. Part II. Passivation and the role of chemical structure of carboxylates," Int. J. Corros. Scale Inhib., 2016, 5, no 4, 282-318. doi: 10.17675/2305-6894-2016-5-4-1

15. I. Frateur, A. Carnot, S. Zanna and P. Marcus, "Role of $\mathrm{pH}$ and calcium ions in the adsorption of an alkyl N-aminodimethylphosphonate on steel: An XPS study," Appl. Surf. Sci., 2006, 252, 2757-2769.

16. A. Paszternák, I. Felhősi, Zs. Keresztes and E. Kálmán, "Formation and Structure of Alkyl-Phosphonic Acid Layers on Passive Iron," Mater. Sci. Forum, 2007, 537-538, 239-246. 
17. A. Paszternák, S. Stichleutner, I. Felhősi， Zs. Keresztes， F. Nagy， E. Kuzmann, A. Vertes, Z. Homonnay, G. Petó and E. Kálmán, "Surface modificationof passive iron by alkyl-phosphonic acid layers," Electrochim. Acta., 2007, 53, 337-345.

18. A. Paszternák, I. Felhősi, Z. Pászti, E. Kuzmann, A. Vértes, E. Kálmán and L. Nyikos, "Surface analytical characterization of passive iron surface modified by alkylphosphonic acid layers," Electrochim. Acta., 2010, 55, 804-812.

19. I.D. Zartsyn, V.B. Shchukin and Kh.S. Shikhaliev, "Formation of Ultrathin Protective Coatings on Low-Carbon Steel from Borate Buffer - Dodecylphosphonic Acid Solution," Prot. Met. Phys. Chem. Surf., 2010, 46, no. 7, 775-781.

20. A.A. Chirkunov, A.S. Gorbachev, Yu.I. Kuznetsov and Kh.S. Shikhaliev, "Inhibition of Anodic Dissolution of Low-Carbon Steel with Alkyl Phosphonate in Borate Buffer Solution," Prot. Met. Phys. Chem. Surf., 2012, 48, no. 7, 769-772. doi: 10.1134/S2070205112070040

21. A.A. Chirkunov, Yu.I. Kuznetsov, N.P. Andreeva and A.S. Gorbachev, "Passivation of mild steel by sodium octylphosphonate in neutral aqueous solution," Int. J. Corros. Scale Inhib., 2017, 6, no. 3, 318-332.

22. Yu.I. Kuznetsov, "Organic corrosion inhibitors: Where are we now? A review. Part I. Adsorption," Int. J. Corros. Scale Inhib., 2015, 4, no. 4, 284-310. doi: 10.17675/23056894-2015-4-4-1

23. W.W. Frenier, "Inhibitors - Development Application for Aqueous Systems," in: Reviews on Corrosion Inhibitor Science and Technology, V. 3, 2004, Houston, NACE International, 6-1-39.

24. Yu.I. Kuznetsov, "The Phosphonate Inhibitors of Metal Corrosion," in: Progress in the Understanding and Prevention of Corrosion, Eds. J.M. Costa and A.D. Mercer, 1993, Cambridge, The University Press, 853-859.

25. Yu.I. Kuznetsov, "Current State of the Theory of Metal Corrosion Inhibition by Phosphonates," Proc. $10^{\text {th }}$ European Symp. Corrosion Inhib., Ferrara, Italy, 2005, V. 1, 233-248.

26. M. Prabakaran, M. Venkatesh, S. Ramesh and V. Periasamy, "Corrosion inhibition behavior of propyl phosphonic acid - $\mathrm{Zn}^{2+}$ system for carbon steel in aqueous solution," Appl. Surf. Sci., 2013, 276, 592-603. doi: 10.1016/j.apsusc.2013.03.138

27. T. Abohalkuma, F. Shawish and J. Telegdi, "Phosphonic acid derivatives used in self assembled layers against metal corrosion," Int. J. Corros. Scale Inhib., 2014, 3, no. 3, 151-159. doi: 10.17675/2305-6894-2014-3-3-151-159

28. F. Roy, A. Et Taouil, F. Lallemand, J.-M. Melot, X. Roizard, O. Heintz, V. Moutarlier and J.-Y. Hihn, "Influence of modification time and high frequency ultrasound irradiation on self-assembling of alkylphosphonic acids on stainless steel: Electrochemical and spectroscopic studies," Ultrason. Sonochem., 2016, 28, 64696472 . 
29. G.N. Fontes, A. Malachias, R. Magalhes-Paniago and B.R.A. Neves, "Structural Investigations of Octadecylphosphonic Acid Multilayers," Langmuir, 2003, 19, 33453349.

30. N.S. McIntyre, H.-Y. Nie, A.P. Grosvenor, R.D. Davidson and D. Briggs, "XPS studies of octadecylphosphonic acid (OPA) monolayer interactions with some metal and mineral surfaces," Surf. Interface Anal., 2005, 37, 749-754.

31. A. Raman, M. Dubey, I. Gouzman and E.S. Gawalt, "Formation of Self-Assembled Monolayers of Alkylphosphonic Acid on the Native Oxide Surface of SS316L," Langmuir, 2006, 22, 6469-6472.

32. Min Soo Lim, K.J. Smiley and E.S. Gawalt, "Thermally Driven Stability of Octadecylphosphonic Acid Thin Films Grown on SS316L," Scanning, 2010, 32, 304-311.

33. A. Raman, R. Quiñones, L. Barriger, R. Eastman, A. Parsi and E.S. Gawalt, "Understanding Organic Film Behavior on Alloy and Metal Oxides," Langmuir, 2010, 26, no. 3, 1747-1754. doi: 10.1021/la904120s

34. C.R. Kaufmann, G. Mani, D. Marton, D.M. Johnson and C.M. Agrawal. "Long-term stability of self-assembled monolayers on 316L stainless steel," Biomed. Mater., 2010, 5, 25008. doi: $10.1088 / 1748-6041 / 5 / 2 / 025008$

35. M. Kosian, M.M.J. Smulders and H. Zuilhof, "Structure and Long-Term Stability of Alkylphosphonic Acid Monolayers on SS316L Stainless Steel," Langmuir, 2016, 32, 1047-1057.

36. D.C. Hansen, "Metal corrosion in the human body: the ultimate bio-corrosion scenario," Electrochemical Soc. Interface, 2008, 17, 31-34.

37. G. Lecollinet, N. Delorme, M. Edely, A. Gibaud, J.-F. Bardeau, F. Hindre, F. Boury and D. Portet, "Self-Assembled Monolayers of Bisphosphonates: Influence of Side Chain Steric Hindrance," Langmuir, 2009, 14, 7828-7835.

38. Yu.I. Kuznetsov, "Role of solution anions in aluminum depassivation and corrosion inhibition," Zashch. Met., 1984, 20, no. 3, 359-372 (in Russian).

39. G.D. Davis, J.S. Ahearn, L.J. Matienzo and J.D. Venables. "Use of hydration inhibitors to improve bond durability of aluminium adhesive joints," J. Mater. Sci., 1985, 20, no. 3, 975-988.

40. R.D. Ramsier, P.N. Henriksen and A.N. Gent, "Adsorption of Phosphorus Acids on Alumina," Surf. Sci., 1988, 203, no. 1, 72-88. doi: 10.1007/BF00585742

41. Ch. Bram, Ch. Jung and M. Stratmann, "Self assembled molecular monolayers on oxidized inhomogeneous aluminum surfaces," Fresenious J. Anal. Chem., 1997, 358, no. $1-2,108-111$.

42. M.J. Pellerite, T.D. Dunbar, L.D. Boardman and E.J. Wood, "Effects of Fluorination on Self-Assembled Monolayer Formation from Alkanephosphonic Acids on Aluminum: Kinetics and Structure," J. Phys. Chem. B, 2003, 107, no. 42, 1172611736. 
43. E. Hoque, J.A. DeRose, P. Hoffmann, H.J. Mathieu, B. Bhushan and M.J. Cichomski, "Phosphonate self-assembled monolayers on aluminum surfaces," J. Chem. Phys., 2006, 124, 174710-1-174710-6.

44. E. Hoque, J.A. DeRose, G. Kulik, P. Hoffmann, H.J. Mathieu and B. Bhushan, "Alkylphosphonate Modified Aluminium Oxide Surfaces," J. Phys. Chem. B, 2006, 110, no. 22, 10855-10861.

45. M. Thieme and H. Worch, "Ultrahydrophobic aluminium surfaces: properties and EIS measurements of different oxidic and thin-film coated states," J. Solid State Electrochem., 2006, 10, no. 9, 737-745. doi: 10.1007/s10008-006-0119-x

46. E. Hoque, J.A. DeRose, P. Hoffmann, B. Bhushan and H.J. Mathieu, "Alkylperfluorosilane Self-Assembled Monolayers on Aluminum: A Comparison with Alkylphosphonate Self-Assembled Monolayers," J. Phys. Chem. C, 2007, 111, 3956-3962.

47. K.M. Pertays, G.E. Thompson and M.R. Alexander, "Self-assembly of stearic acid on aluminium: the importance of oxide surface chemistry."Surf. Interface Anal. 2004. 36. 1361-1366, doi: 10.1002/sia.1919

48. I.L. Liakos, R.C. Newman, E. McAlpine and M.R. Alexander, "Study of the Resistance on Aluminium to Acidic and Basic Solutions Using Dynamic Contact angle Measurement." Langmuir, 2007, 23, 995-999.

49. T.T. Foster, M.R. Alexander, G.J. Leggett and E. McAlpine, "Friction Force Microscopy of Alkylphosphonic Acid and Carboxylic Acids Adsorbed on the Native Oxide of Aluminum," Langmuir, 2006, 22, 9254-9259.

50. J.A. DeRose, E. Hoque, B. Bhushan and H.J. Mathieu, "Characterization of perfluorodecanoate self-assembled monolayers on aluminum and comparison of stability with phosphonateand siloxy self-assembled monolayers," Surf. Sci., 2008, 602, 1360-1367.

51. P. Thissen, M. Valtiner and G. Grundmeier, "Stability of Phosphonic Acid SelfAssembled Monolayers on Amorphous and Single-Crystalline Aluminum Oxide Surfaces in Aqueous Solution," Langmuir, 2009, 26, no. 1, 156-164.

52. T. Hauffman, L. Van Lokeren, R. Willem, A. Hubin and H. Terryn, "In Situ Study of the Deposition of (Ultra)thin Organic Phosphonic Acid Layers on the Oxide of Aluminum," Langmuir, 2012, 28, 3167-3173.

53. T. Hauffman, T. Breugelmans, Y. Van Ingelgem, E. Tourwe, H. Terryn and A. Hubin, "Measuring the adsorption of ethanol on aluminium oxides using odd random phase multisine electrochemical impedance spectroscopy." Electrochem. Commun., 2012, 22, $124-127$.

54. T. Hauffman, Y. Van Ingelgem, T. Breugelmans, E. Tourwe, H. Terryn and A. Hubin, "Dynamic, in situ study of self-assembling organic phosphonic acid monolayers from ethanolic solutions on aluminium oxides by means of odd random phase multisine electrochemical impedance spectroscopy," Electrochim. Acta., 2013, 106. 342-350.

55. Jun-e Qu, Geng Chen, Hai-ren Wang and De-jian Nie, "Effect of water content on corrosion inhibition behavior of self-assembled TDPA on aluminum alloy surface," Trans. Nonferrous Met. Soc. China., 2013, 23, 3137-3144. 
56. H. Sato, T. Fujii, E. Tsuji, Y. Aoki, K. Shimizu, P. Skeldon, G.E. Thompson and H. Habazai, "Observation of self-assembled layers of alkyl phosphonic acid on aluminum using low-voltage scanning electron microscopy and AFM," Surf. Interface Anal., 2013, 45, 1441-1445.

57. M. Giza, P. Tissen and G. Grandmeier, "Adsorption Kinetics of Organophosphonic Acids on Plasma-Modified Oxide-Covered Aluminum Surfaces," Langmuir, 2008, 24, 8688-8694.

58. B. Branch, M. Dubey, A.S. Anderson, K. Artyushkova, J.K. Baldwin, D. Petsev and A.M. Dattelbaum, "Investigating phosphonate monolayer stability on ALD oxide surfaces," Appl. Surf. Sci., 2014, 288, 98-108.

59. J. Telegdi, G. Luciano, S. Mahanty and T. Abohalkuma, "Inhibition of aluminum alloy corrosion in electrolytes by self assembled fluorophosphonic acid molecular layer," Mater. Corros., 2016, 66, no. 12, 1382-1390.

60. I. Maege, E. Jaehne, A. Henke, H.-Ju.P. Adler, Ch. Bram, Ch. Jung and M. Stratmann, "Self-assembling adhesion promoters for corrosion resistant metal polymer interfaces," Progr. Org. Coat., 1998, 34, 1-12.

61. K. Wapner, M. Stratmann and G. Grundmeier, "Structure and stability of adhesion promoting aminopropyl phosphonate layers at polymer/aluminium oxide interfaces," Int. J. Adhes. Adhes., 2008, 28, no. 1-2, 59-70.

62. S. de Souza, D.S. Yoshikawa, W.A.S. Izaltino, S.L. Assis and I. Costa, "SelfAssembling Molecules as Corrosion Inhibitors for 1050 Aluminum," Surf. Coat. Technol., 2010, 204, no. 20, 3238-3242. doi: 10.1016/j.surfcoat.2010.03.021

63. W. Ma, H. Wu, Y. Higaki, H. Otsuka and A. Takahara, "A 'non-sticky' superhydrophobic surface prepared by self-assembly of fluoroalkyl phosphonic acid on a hierarchically micro/nanostructured alumina gel film," Chem. Commun., 2012, 48, 6824-6826.

64. S. Attavar, M. Diwekar, M.R. Linford, M.A. Davis and S. Blair, "Passivation of aluminum with alkyl phosphonic acids for biochip applications," Appl. Surf. Sci., 2010, 256, 7146-7150.

65. T. Ishizaki, K. Teshima, Y. Masuda and M. Sakamoto, "Liquid phase formation of alkyl- and perfluoro-phosphonic acid derived monolayers on magnesium alloy AZ31 and their chemical properties," J. Colloid Interface Sci., 2011, 360, 280-288.

66. Z. Grubač, M. Metikoš-Huković, R. Babić, I.Š. Rončević, M. Petravić and R. Peter, "Functionalization of biodegradable magnesium alloy implants with alkylphosphonate self-assembled films," Mater. Sci. Eng C., 2013, 33, 2152-2158.

67. T. Ishizaki, M. Okido, Y. Masuda, N. Saito and M. Sakamoto, "Corrosion Resistant Performances of Alkanoic and Phosphonic Acids Derived Self-Assembled Monolayers on Magnesium Alloy AZ31 by Vapor-Phase Method," Langmuir, 2012, 27, 6009-6017.

68. A. Mahapatro, T.D.M. Negrón and A. Nguyen, "Spectroscopic Evaluations of Interfacial Oxidative Stability of Phosphonic Nanocoatings on Magnesium," $J$. Spectrosc., 2015, 1-8. doi: $\underline{10.1155 / 2015 / 350630}$ 
69. B.M. Silverman, K.A. Wieghaus and J. Schwartz, "Comparative Properties of Siloxane vs Phosphonate Monolayers on A Key Titanium Alloy," Langmuir, 2005, 21, 225-228.

70. G. Zorn, I. Gotman, E.Y. Gutmanas, R. Adadi, G. Salitra and C.N. Sukenik, "Surface Modification of Ti45 Nb Alloy with an Alkylphosphonic Acid Self-Assembled Monolayer," Chem. Mater., 2005, 17, 4218-4226.

71. N. Adden, L.J. Gamble, D.G. Castner, A. Hoffmann, G. Gross and H. Menzel, "Synthesis and Characterization of Biocompatible Polymer Interlayers on Titanium Implant Materials," Biomacromolecules, 2006, 7, 2552-2559.

72. R. Adadi, G. Zorn, R. Brener, I. Gotman, E.Y. Gutmanas and C.N. Sukenik, "Phosphonate-anchored thin films on titanium and niobium oxide surfaces: Fabrication and characterization," Thin Solid Films, 2010, 518, 1966-1972.

73. A. Kanta, R. Sedev and J. Ralston, "The formation and stability of self-assembled monolayers of octadecylphosphonic acid on titania," Colloids Surf., A, 2006, 291, 5158.

74. Z. Petrović, J. Katić, M. Metikos-Huković, H. Dadafarin and S. Omanovic, "Modification of a Nitinol Surface by Phosphonate Self-Assembled Monolayers," J. Electrochem. Soc., 2011, 158, no. 10, F159-165.

75. C. Zhang, Y. Liu, Sh. Wen and J. Luo, "Insight into the formation mechanism of durable hexadecylphosphonic acid bilayers on titanium alloy through interfacial analysis," Colloids Surf., A, 2014, 447, 51-58.

76. N. Metoki, L. Liu, E. Beilis, N. Eliaz and D. Mandler, "Preparation and Characterization of Alkylphosphonic Acid Self-Assembled Monolayers on Titanium Alloy by Chemisorption and Electrochemical Deposition," Langmuir, 2014, 30, 67916799.

77. Yu.I. Kuznetsov and L.P. Kazansky, "Physicochemical aspects of metal protection by azoles as corrosion inhibitors," Russ. Chem. Rev., 2008. 77, no. 3, 219-232.

78. S. Ramesh, S. Rajeswari and S. Maruthamuthu, "Corrosion inhibition of copper by new triazole phosphonate derivatives," Appl. Surf. Sci., 2004, 229, 214-225.

79. T. Keszthelyi, Z. Paszti, T. Rigo, O. Hakkel, J. Telegdi and L. Guczi, "Investigation of Solid Surfaces Modified by Langmuir-Blodgett Monolayers Using Sum-Frequency Vibrational Spectroscopy and X-ray Photoelectron Spectroscopy," J. Phys. Chem. B., 2006, 110, 8701-8714.

80. E. Hoque, J.A. DeRose, B. Bhushan and K.W. Hipps, "Low adhesion, non-wetting phosphonate self-assembled monolayer films formed on copper oxide surfaces" Ultramicroscopy, 2009, 109, no. 8, 1015-1022.

81. Y. Wan, Y. Wang, Q. Zhang, Z. Wang, Z. Xu, Ch. Liu and J. Zhang, "Enhanced tribology durability of a self-assembled monolayer of alkylphosphonic acid on a textured copper substrate," Appl. Surf. Sci., 2012, 259, 147-152.

82. M.M. Moine, X. Roizard, J.-M. Melot, L. Carpentier, P.-H. Cornuault, F. Lallemand, J.-M. Rauch, O. Heintz and S. Lallemand, "Grafting and characterization of dodecyl- 
phosphonic acid on copper: Macro-tribological behavior and surface properties," Surf. Coat. Technol., 2013, 232, 567-574.

83. Ch. Dai, N. Liu, Y. Cao, Y. Chen, F. Lua and L. Feng, "Fast formation of superhydrophobic octadecylphosphonic acid (ODPA) coating for self-cleaning and oil/water separation," Soft Matter, 2014, 10, 8116-8121.

84. K.M. Kruszewski, E.R. Renk and E.S. Gawalt, "Self-assembly of organic acid molecules on the metal oxide surface of a cupronickel alloy," Thin Solid Films, 2012, 520, 4326-4331.

85. S. Manov, A.M. Lamazouere and L. Aries, "Electrochemical study of the corrosion behaviour of zinc treated with a new organic chelating inhibitor," Corros. Sci., 2000, 42, no. 7, 1235-1248. doi: 10.1016/S0010-938X(99)00132-8

86. F. Sinapi, L. Forget, J. Delhalle and Z. Mekhalif, "Formation and characterization of thin films of $\mathrm{H}\left(\mathrm{CH}_{2}\right)_{x} \mathrm{PO}(\mathrm{OH})_{2}$ on polycrystalline zinc substrates," Surf. Interface Anal., 2002, 34, no. 1, 148-154.

87. A. Pilbáth, I. Felhősi, G. Tolnai and E. Kálmán, "Application of self-assembly for replacing chromate in corrosion protection of zinc," J. Solid State Electrochem., 2006, 10, no. 9, 721-729.

88. A. Pilbáth, I. Bertoti, I. Sajo, L. Nyikos and E. Kálmán, "Diphosphonate thin films on zinc: Preparation, structure characterization and corrosion protection effects," Appl. Surf. Sci., 2008, 255, 1841-1849.

89. A. Pilbáth, L. Nyikos, I. Bertoti and E. Kálmán, "Zinc Corrosion protection with 1,5diphosphonopentane," Corros. Sci., 2008, 50, 3314-3321.

90. C.L. Perkins, "Molecular Anchors for Self-Assembled Monolayers on ZnO: A Direct Comparison of the Thiol and Phosphonic Acid Moieties," J. Phys. Chem. C, 2009, 113, $18276-18286$.

91. P.J. Hotchkiss, M. Malicki, A.J. Giordano, N.R. Armstrong and S.R. Marder, "Characterization of phosphonic acid binding to zinc oxide," J. Mate. Chem., 2011, 21, 3107-3112. doi: 10.1039/C0JM02829K

92. M.S. White, D.C. Olson, S.E. Shaheen, N. Kopidakis and D.S. Ginley, "Inverted bulkheterojunction organic photovoltaic device using a solution-derived $\mathrm{ZnO}$ underlayer," Appl. Phys. Lett., 2006, 89, id. 143517. doi: 10.1063/1.2359579

93. A. Bulusu, S.A. Paniagua, B.A. MacLeod, A.K. Sigdel, J.J. Berry, D.C. Olson, S.R. Marder and S. Graham. "Efficient Modification of Metal Oxide Surfaces with Phosphonic Acids by Spray Coating," Langmuir, 2013, 29, no. 12, 3935-3942.

94. A. Ostapenko, T. Klöffel, B. Meyer and G. Witte, "Formation and Stability of Phenylphosphonic Acid Monolayers on ZnO: Comparison of In Situ and Ex Situ SAM Preparation," Langmuir, 2016, 32, no. 20, 5029-5037.

95. H.-L. Yip, S.K. Hua, N.S. Baek, H. Ma and A.K.-Y. Jen, "Polymer solar cells that use self-assembled monolayer-modified $\mathrm{ZnO} /$ metals as cathodes," J. Adv. Mater., 2008, 20/12, 2376-2382. doi: 10.1002/adma.200703050 
96. R. Quiñones, A. Raman and R.J. Luliucci, "Investigation of phosphonic acid surface modifications on zinc oxide nanoparticles under ambient conditions," Thin Solid Films, 2014, 565, 155-164.

97. P. Thissen, J. Wielant, M. Köyer, S. Toews and G. Grundmeier, "Formation and stability of organophosphonic acid monolayers on ZnAl alloy coatings," Surf. Coat. Tehnol., 2010, 204, 3578-3584.

98. K. Pohl, J. Otte, P. Thissen, M. Giza, B. Shuhmacher and G. Grundmeier, "Adsorption and stability of self-assembled jrganophosphonic acid monolayers on plasma modified Zn-Mg-Al alloy surface," Surf. Coat. Tehnol., 2013, 218, 99-107.

99. R. Quiñones, A. Raman and E.S. Gawalt, "Functionalization of nickel oxide using alkylphosphonic acid self-assembled monolayers," Thin Solid Films, 2008, 516, 87748781 .

100. R. Bhure, T.M. Abdel-Fattah, C. Bonner, J.C. Hall and A. Mahapatro, "Formation of nanosized phosphonic acid self assembled monolayers on cobalt-chromium alloy for potential biomedical applications," J. Biomed. Nanotechnol., 2010, 6, 117-128.

101. R. Bhure, T. Abdel-Fattah, C. Bonner, F. Hall and A. Mahapatro, "Stability of phosphonic self assembled monolayers (SAMs) on cobalt chromium (Co-Cr) alloy under oxidative conditions," Appl. Surf. Sci., 2011, 257, 5605-5612.

102. Ch. Kaufmann, G. Mani, D. Marton, D. Johnson and C.M. Agrawal, "Long-term stability of self-assembled monolayers on electropolished L605 cobalt chromium alloy for stent applications," J. Biomed. Mater. Res., Part B, 2011, 988, no. 2, 280-289.

103. R. Bhure, A. Mahapatro, C. Bonner and T. Abdel-Fattah, "In vitro stability study of organophosphonic self assembled monolayers (SAMs) on cobalt chromium $(\mathrm{Co}-\mathrm{Cr})$ alloy," Mater. Sci. Eng. C., 2013, 33, 2050-2058.

104. K. Jo and H. Yang, "Comparative study of stability of phosphonate self-assembled monolayers on indium-tin oxide electrodes prepared using different methods," $J$. Electroanal. Chem., 2014. 712, 8-13. 